\title{
An Appraisal of Current and Future Needs in Ultrasonic NDE Standards
}

G. Birnbaum and D. G. Eitzen

National Bureau of Standards

Washington, D.C. 20234

October 1979

Report to

Defense Advanced Research Projects Agency 1400 Wilson Boulevard

Arlington, VA 22209 



\section{AN APPRAISAL OF CURRENT AND FUTURE NEEDS IN ULTRASONIC NDE STANDARDS}

G. Birnbaum and D. G. Eitzen

National Bureau of Standards

Washington, D.C. 20234

October 1979

Report to

Defense Advanced Research Projects Agency 1400 Wilson Boulevard

Arlington, VA 22209

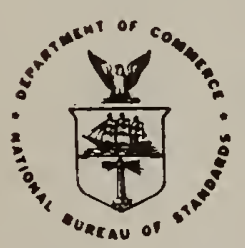

U.S. DEPARTMENT OF COMMERCE, Juanita M. Kreps, Secretary Luther H. Hodges, Jr., Under Secretary Jordan J. Baruch, Assistant Secretary for Science and Technology NATIONAL BUREAU OF STANDARDS, Ernest Ambler, Director 

1. INTRODUCTION 3

2. INPUT DATA 6

2.1 Historical-Background 6

2.2 Workshop on U1trasonic NDE Standards, October 1977

2.3 Documentary Standards 9

2.4 Literature References 10

3. ANALYSIS AND PERSPECTIVE 11

3.1 The Role of Standards 11

3.1.1 General nature of standards 11

$\begin{array}{lll}3.1 .2 & \text { Ultrasonic NDE standards } & 12\end{array}$

3.1.3 U1trasonic NDE standards organizations in the U.S. 13

3.2 Framework for Assessing U1trasonic NDE Standards 14

3.2.1 Nature of an u1trasonic flaw detection system $\quad 14$

3.2.2 Uses of a standard 15

3.2.3 Criteria for evaluating possible standards 16

3.3 An Approach to a Systematic Examination of Ultrasonic Reference Blocks

3.3.1 Introduction 17

3.3.2 Analysis of block design 18

3.3.3 An example of the critique of a proposed standard 22

3.4 The Characterization of Ultrasonic Transducers for NDE 26

3.5 Standards Implications of New U1trasonic NDE Techniques. $\quad 30$

4. OUTPUTS OF THIS STUDY 33

4.1 Key Issues 33

4.1.1 What are the standards requirements for 33 quantitative NDE?

4.1.2 What is the impact of computer-based systems and 33 advanced signal processing on standards requirements? 
4.1.3 Herarchy of standards

4.1.4 Is there a "super" block that does everything?

4.1.5 Overall versus separate component callbration

4.1.6 Why be concerned about trying to improve current standards for pulse echo techniques when better techniques are around the corner?

4.1.7 What are the tolerances on reference blocks and transducers that are really required?

4.1.8 What are the requirements for transducer

4.1.9 With the many advances in electronic technology, why are there problems in calibrating the electronic equipment?

4.1.10 What about standards for measurements of residual stress and materials properties? a."

4.2 Recommendations for Research and Development of

Ultrasonic NDE Standards

4.2.1 Improvements in standards for existing systems

4.2.2 Proposed methods for standardization and calibration

4.2.3 Standards needs for developing methods; quantitative NDE

4.3 Priorities, Impact, Final Comments

4.3.1 There are a great many problems but what are the priorities?

4.3.2 If all the problems are solved, what Impact can be expected?

4.3.3 Final comments 


\section{SUMMARY}

The purpose of this study, supported in part by DARPA, is to assess the current status of ultrasonic NDE standards and calibrations and to determine current and future needs in this area. The source material includes surveys of the literature and patents, a study of foreign practice, surveys of NBS and consensus standards (e.g., ASTM) programs, discussions, visits and letters, and a Workshop on U1trasonic NDE Standards: "Current Needs and Future Directions," held October 17-18, 1977 for the purpose of implementing the objectives of this study. This resource material is critically analyzed: 1. to determine what needs to be done to improve existing standards; 2 . to select for further evaluation proposed standards and calibration methods; and 3 . to assess the requirements for standards and calibration for developing ultrasonic systems. Following this analysis, we make recommendations for work in three areas which should provide the basis for an approach to a system of ultrasonic NDE standards. In the first part, we recognize that improvement of accepted standards, e.g. those proposed by ASTM, those traceable to NBS or those widely used in practice, will have an immediate and cost effective impact on improving the reliability and more quantitative use of current methods. It is also clear that improvements in these standards, in the underlying theory and in their relation to practice will have significant, direct impact on future systems. The second part deals with proposed methods which are new rather than improvements to those considered in the first part. The emphasis here is not on unexplored ideas but rather on the examination and possible implementation of the concepts for specific standards needs. The third part deals with standards and calibration needs for evolving and future ultrasonic NDE methods.

Recommendations for improvement in existing standards will impact primarily on conventional pulse echo systems and include work on transducers, the electronic system and reference blocks. The fields produced by transducers are complex and the variability is high. Thus an important aspect of the transducer characterization problem is the need for a better understanding of the experimental and theoretical nature of transducers to develop minimum specifications to obtain reproducible results in flaw evaluation. Simflar considerations apply in the characterization of the electronics. What are the right things to be measured and how should they be measured? The electronics and transducer calibration problems are not so much how to do it but what to do. In the areas of blocks, the development of quartz blocks free of the material problems of metal blocks is a promising future direction. However, a new problem, that of transferring the calibration to metal components, must be solved. 
Many methods of standardization and calibration have been proposed; these seem to offer logical or practical advantages over currently accepted methods but are not widely used or used at all. These methods should be completely analyzed with a proper set of criteria and promoted if they indeed prove to be significantly advantageous. As an example of this process, we have examined the possibility of using theoretically characterized scatterers such as spheres where the theoretical knowledge of the scattering cross section is to play a crucial role in the calibration process. Although this feature would appear to be attractive, we find that some of the advantages claimed for the method are really not important in practice and that further work is necessary. On the other hand, this study indicates that theory may play a significant role in aiding the transfer of a calibration to different conditions, for example, frequency and bandwidth.

We finally consider the standards needs for developing techniques. Two of the major needs which motivate these developments are quantitative measurements of flaw geometry, orlentation and size and a decrease in the dependence on operator interpretation. The coupling of minicomputers to NDE equipment and the use of adaptive and imaging systems appear to make such hopes real. What are the standards requirements of such systems? Do such systems need standards? Our analysis of the problem leads us to suggest that more complex systems will require more careful characterization and more complex reference standards. Exactly what these will be is the subject of further research. However, it appears even at this stage that some of the necessary standards might not be too different from many that are in current use. 


\section{SECTION I}

\section{INTRODUCTION}

The objectives of this study are to examine the present system of standards for ultrasonic nondestructive evaluation (NDE) measurements, to assess the standards need of emerging and more quantitative systems and to present recommendations for the development of an adequate and integrated system of standards for quantitative ultrasonic NDE. Although the focus is primarily on pulse echo techniques (as would be anticlpated by their widespread use) we do not neglect other and newer techniques such as scattering, Fourier transform and imaging systems.

Realizing these objectives has proven to be a difficult task because of the many uncoordinated standards and calibrations already in existence, the wide variety of materials, geometries, defect types and instrumentation. Added to this are the newer more difficult

requirements of quantitative measurements which involve new specialized techniques. This diversity is compounded by the fact that the quantity measured in many cases is not a primary quantity such as length but a derived quantity such as reflectivity which is only indirectly related to (defect) length.

Since meeting the objectives of this study entailed a greater effort than had been anticipated, we have previously provided several outputs to meet the needs of the sponsor. These outputs are incorporated in Section 4, which contains Key Issues, Recommendations, and Priorities, in short a plan for attacking the problem.

We wish to stress that this study is not one of hard science. In many cases recommendations have had to be based on partial information, opinions and even educated guesses. Hence, it is not surprising that a number of our recommendations are aimed at developing a better technical basis for assessing what needs to be done to establish a proper basis for ultrasonic NDE standards. Finally, it should be emphasized that this report does not represent our final word in this area. It is hoped that the comments to be received concerning this work will be used to update the analysis and findings.

In scope, this report includes a section on various input data including a history of the problem, a brief discussion of the Ultrasonic NDE Standards Workshop, discussed in detail in Appendix A, and brief mention of a review of literature references and documentary standards which are published separately. However, this by no means represents the total input to this study which also included numerous conversations with many workers in the field and the wide experience of many members of the NBS staff. In Section 3, we deal with the role of standards in general and with many questions relating to ultrasonic NDE standards in particular. A new framework for assessing ultrasonic NDE standards ${ }^{1}$

Developed primarily by N. Hsu. 
is presented, the question of transducer characterization is examined and the standards implications of new techniques are considered. Also included in this section is a discussion of how one might systematically examine proposed ultrasonic reference blocks for use as possible standards. In order to gain additional perspective from hands-on experience with reference blocks, a qualitative study conducted primarily by N. Hsu and $W$. Sachse was completed on some novel blocks; this is reported in Appendix B. Section 4 gives a plan of action, namely the recommendations for research and their priorities. This section is introduced by a discussion of key issues which constitutes the rationale for the plan.

Work not included in this document but considered to be part of this study includes:

o A Comparison of American and European Ultrasonic Testing Standards, S. Golan, National Bureau of Standards Interagency Report, NBSIR 79-1790.

o Ultrasonic Transducers for Materials Testing and Their Characterization, W. Sachse, N. Hsu, Physical Acoustics, Vol. 14 .

- Summary of the Literature on U1trasonic NDE Standards, D. G. Eitzen and G. Birnbaum, National Bureau of Standards Interagency Report, to be published.

These documents grew so large in scope that they required separate publication in their own right.

A laboratory study on new block concepts was inftiated to provide hands-on experience and to assist in the evaluation of block concepts. The study was supported by NBS when it was recognized as a beneficial adjunct to this DARPA project.

This report and the reports cited above are intended to be resource documents in the area of ultrasonic measurements and particularly in standards and calibrations. In addition, this report, particularly Section 4, Output, is meant to provide a basis for planning a unified approach to the realization of a system of ultrasonic NDE standards.

In the NDE field there are certain terms relating to standardization, which are used with lack of precision - calibration, standard, reference standard, etc. The problem of definitions is a serious one. For example, the ASTM glossary on NDE contains about fifteen definttions of the term "calibration". Our first recommendation in this report is that the problem of word usage and definitions be studled and resolved. Organizations such as ASNT and ASTM would seem to be most sulted for such a task. In the body of this report, we have used such terms as callbration, standard and product standard with 
approximately the following meanings: calibration - to compare or adjust instrument readings in accordance with recognized units of measure, often artifacts and procedures are required to accomplish this; standard - an artifact, standard procedure or document or a generic term which may include the calibration process; product standard - an actual part with a known defect. In addition, the term defect is used interchangeably with discontinuity although they are clearly not synonomous. In any case it is hoped that the context will make reasonably clear our meaning for such terms.

The major contributors to the overall program are G. Birnbaum, D. E1tzen, S. Golan, N. Hsu and W. Sachse. However, the responsibility for this report and the opinions and prejudices therein are due to $G$. Birnbaum and D. Eitzen. These authors wish to thank H. Berger for his continual interest and enthusiastic support of this effort. We also thank Dr. L. Mordfin for his many helpful comments on this manuscript. One of us (G.B.) thanks M. Buckley for several stimulating conversations in which a number of the 1ssues were debated. It is Dr. Buckley who encouraged the writing of a "gutsy" report and it may not be too much to hope that this report in some sense meets this challenge. 


\section{SECTION II}

\section{INPUT DATA}

\subsection{HISTORICAL BACKGROUND}

Almost as soon as commercial pulse-echo ultrasonic flaw detection instruments were available in this country (about 1944), the need for suitable calibration methods for the ultrasonic measurement system was recognized. The early uses of ultrasonics were qualitative and the need for a calibration method was perceived as one for equipment checkout and for reproducibility of a test at a site. Many organizations had responded to this need primarily with internal organizational solutions. In this country reference blocks with different sized artificial defects and with the same distance between the ultrasonic entry surface and the artificial reflector (constant metal travel distance) were produced by organizations including Sperry, Alcoa, Grumman and Ultrasonic Testing and Research Labs [1] ${ }^{2}$. These blocks were primarily used for longitudinal wave testing. Reference blocks for angle beam and shear wave testing have also been produced. These include:

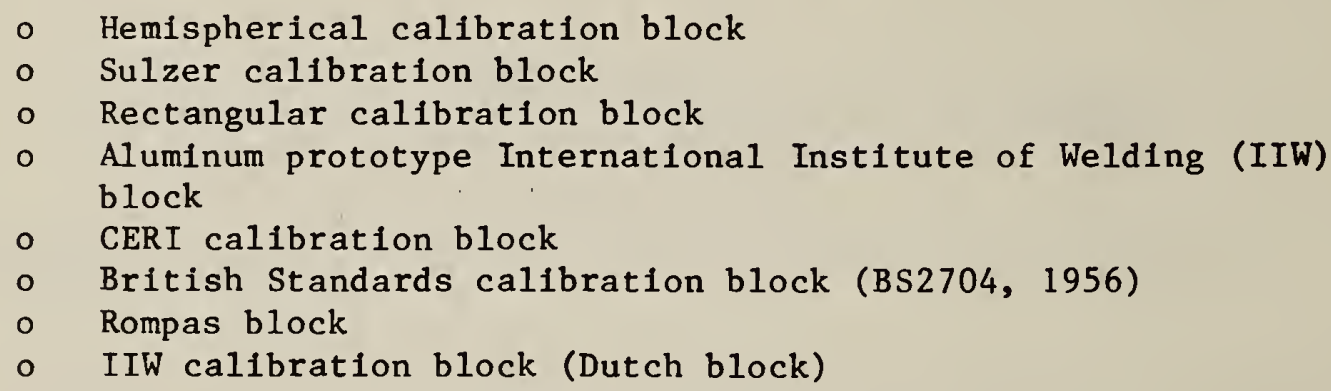

Of these blocks the IIW block, evaluated by Commission $V$ of IIW from 1955 to 1959 [2] is probably the most widely accepted for angle beam testing. Some of these blocks were also designed for use in longitudinal contact testing. All of the blocks discussed so far were designed for checking some characteristics of the measurement system and for setting sensitivity. They were not designed as defect standards and should not be used to estimate the magnitude of defects [3].

In the $1950^{\circ} \mathrm{s}$, reference blocks with different metal travel distances were being produced by several organizations and these blocks were employed as comparison standards for the acceptance of parts or stock and for a coarse estimate of flaw size. Most organizations producing these distance/amplitude type reference blocks had agreed on the use of flat bottomed holes as the reflector for producing a return

2 Figures in brackets indicate the literature references at the end of the paper. 
echo for comparison with an actual defect in flaw estimation. Flat bottomed holes were used because of the "known" area of the reflector and because the flat reflector was judged more closely to resemble several types of metallurgical discontinuities. There are, however, some organizations who still use the cylindrical surface of a side drilled hole as the reference reflector.

In this country the need for standardizing the systems of reference blocks being used was recognized by portions of the airframe industry, DoD, and metals suppliers and in 1951 a task group was set up within ASTM to standardize the reference system. The need for a primary reproducible industry-wide standard with which to intercompare different reference blocks was recognized. By 1958 ball bearings were accepted by the ASTM task group as a primary standard. Also the details of block geometry and material for the flat bottomed hole type secondary reference standards and block evaluation procedure were agreed upon. The critical part of this evaluation of the secondary reference standards involves the comparison of the amplitude of the signal reflected from a specific ball bearing immersed in water with the amplitude of the signal reflected from the flat bottomed hole in the immersed reference blocks.

A recommended practice for the fabrication and evaluation of aluminum ultrasonic reference blocks was published by ASTM (127-58T) [4] in 1958. In the late $1960^{\circ} \mathrm{s}$, it became clear to the ASTM committee that this practice was no longer appropriate or even capable of being accomplished [5]. Newly fabricated sets of reference blocks did not behave in the required manner and the differences in response between nominally identical references were unacceptable. 3 Part of the problem was thought to be due to changes in the specification of the aluminum alloy selected. A new revision of the recommended practice was published in 1975 as E127-75 [7]. In the revision the evaluation of the reference blocks was made much less sensitive by examining the relationship of the blocks to the ball reflectors at $5 \mathrm{MHz}$ rather than the previously specified $15 \mathrm{MHz}$. Also, the tolerance on the allowable amplitude of response from the reference blocks was increased to \pm 25 percent rather than the previously specified \pm 10 percent. This ASTM development of aluminum reference blocks in many respects shaped the development of steel reference blocks embodied in ASTM recommended practice E428-71 [8]. However, there is no primary standard for the steel reference blocks and no method for evaluating their ultrasonic response. Blocks from many other materials are made to the dimensions of $\mathrm{E} 428-71$.

Effort on the development of flat bottomed hole type reference blocks has been paralleled abroad. For example, the AQD Labs. (then AID Labs.) in the United Kingdom began a block development program in

3 Data taken at NBS shows 40 percent differences to be common and that one set differs from the average by 700 percent [6]. 
1954. A set of primary reference blocks were selected in 1962. The U.K. block geometry and material is somewhat simflar to that in ASTM E127-58 but one particular set is defined as the primary set. Secondary and working sets are assigned correction factors with an uncertainty of about \pm 12 percent by direct comparison with the primary set [9].

The following statement made in 1962 is still true today: "While it [1s] admitted that a number of ultrasonic standards are in use today, none of these has general application; standards elther apply to some specific product or material, or they are issued by a particular body or inspection authority and are limited in application" [10].

Despite this bleak picture on the status of ultrasonic NDE standards, a number of encouraging signs have appeared on the horizon. With some strong encouragement from the Air Force Materials Lab and with growing internal awareness, NBS began a program in ultrasonic NDE standards in 1973 which was later formalized and coordinated through the office of NDE. The point here worthy of note is the program focus on NDE standards. Strong attempts were made to get input and coordinate this standards effort through meetings such as the NBS NDE Public Review and Workshop in 1974 and the Symposium on NDT Standards sponsored by NBS, ASTM and ASNT in 1976.

Also, during this general time frame increased interest in ultrasonic testing at many of the $R$ and $D$ laboratories was apparent; some of this effort was also devoted to work on standards. By way of example, the large ARPA/AFML effort at Rockwell International, the work at NRL and the work at Battelle and SWRI have had identiflable components relevant to standardization of ultrasonic NDE. It is of interest to note that in the last two examples, some of the effort focused not on reference blocks but on transducers. This broadening of the attention of standardization of ultrasonic testing to areas in addition to reference blocks is particularly evident in some of the recent ASTM activity. A comprehensive effort has been launched to improve the overall standardization of ultrasonic systems, standardization of electronic subcomponents and transducers and improved testing practices. The test block effort is still vigorous and there is an active program within ASTM and elsewhere to reduce varlability [11]. This interest in test blocks is certainly reflected in this report; see Sections $3.2,3.3,4.1 .4$, and Appendix B.

We note that the parallel standardization efforts (e.g. American Institute of Ultrasound in Medicine) for medical ultrasonic applications have to a large measure shown a simflar broadening to include transducers and electronic subcomponents. It seems evident that interactions between these parallel groups on progress in measurement and standardization efforts could mutually benefit both communities. Although we do not deal with standards and practices in medical applications, it is emphasized that interactions between the medical and NDE communities should be implemented. 
Finally, at the suggestion of DARPA, this study was undertaken to take a look at the standards for ultrasonic NDE measurements and to present a course of action for the development of an adequate system of standards and calibrations ${ }^{4}$. However, it is interesting to note that the need for this study was further relnforced by the range of opinions and diversity of needs which came out of the Workshop on U1trasonic NDE Standards conducted as a part of this project.

\subsection{WORKSHOP ON ULTRASONIC NDE STANDARDS, OCTOBER 1977}

To meet the objectives of this study, 1t was necessary to promote first hand exchange of the most current information on ultrasonic NDE standards. To this end a Workshop on Ultrasonic Nondestructive Evaluation Standards: Current Needs and Future Directions was held October 17-18, 1977 at the National Bureau of Standards, Gaithersburg, Haryland. A number of individuals experienced in varlous aspects of ultrasonic testing and research and representing industry, government and the academic community participated in the workshop. One of the experts noted that "If this group (workshop attendees) cannot 1dentify what should be done [about ultrasonic NDE standards], then there is not another group in the United States that can." The workshop provided a forum for the discussion of the status of current ultrasonic NDE standards, ultrasonic NDE needs in industry and government and recent developments in ultrasonic NDE and their implications for standards.

A detalled summary of this workshop, the program and list of participants are given in Appendix A. In order to encourage free discussion, It was stated that the authors of the comments would not be identifled. Some of the most significant points discussed and debated at the workshop form the basis for many of the key issues in Section 4.1. In addition, the proceedings of the workshop are reflected in the recommendations 4.2 and had significant impact on various other aspects of this report.

\subsection{DOCUMENTARY STANDARDS}

Documentary standards were reviewed under this effort in some detall in a separate publication by S. Golan [12]. We expect this review to be most useful to people interested in developing or changing documentary standards rather than to the general users of such standards.

In this review twenty-seven general ultrasonic standards from nine industrialized countries and two international organizations, ISO (International Organization for Standardization) and IIW (International Institute for Welding), are summarized and evaluated. The standards which are reviewed cover the following areas: characterization and evaluation of ultrasonic systems and transducers, standard reference

\footnotetext{
${ }^{4}$ This work was supported by Advanced Research Projects Agency (ARPA Order Number 3374) and the National Bureau of Standards.
} 
blocks and descriptions of methods and procedures. The standards were evaluated according to the following criterla: simplicity, frequency of reference in specific product standards and amount and quality of

information. In the summary of the review a discussion of the "universal" approach versus the "specific" product orlented approach is given.

\subsection{LITERATURE REFERENCES}

As resource material for this and future investigations almed at developing and improving ultrasonic NDE standards, an examination of the 11 terature was conducted. The scope of the survey includes journal references and internal reports on ultrasonic NDE standards, procedures, calibrations and reference blocks from the $50^{\circ} \mathrm{s}$ to near the present. Abstracts from all the citations were obtained. Although the collection is not exhaustive, it grew so large that it is published under separate cover as "Summary of the Literature on U1trasonic NDE Standards," by D. E1tzen and G. Birnbaum [13]. The cltations on transducers are to be found in the article "Ultrasonic Transducers for Materials Testing and Their Characterization" by W. Sachse and N. Hsu [14]. 


\section{SECTION III}

\section{ANALYSIS AND PERSPECTIVE}

\subsection{THE ROLE OF STANDARDS}

We present in this section a brief description of the role of standards in general and more particularly as applied to (ultrasonic) NDE.

\subsubsection{General nature of standards}

What is the role of standardization in a measurement? One of the first requirements is to provide a scale or a metric which defines the unit of the quantity being measured. In many cases the standard is provided by an artifact such as the kilogram mass or the early meter bar. More recently the latter has been replaced by an agreed-upon wavelength definition of the meter which can be experimentaliy realized by following a specified procedure to gain access to this unit of length. By itself the use of an appropriate standard is not sufficient to give a reproducible measurement. A procedure for using the standard and a measurement apparatus is needed to give a signal which is characteristic of the quantity being measured. If in addition a proper measurement procedure is followed, then different people at various times and places can realize similar results in measuring the same quantity.

The use of an unambigusus unit for length, weight, time, etc. implies that there be a unique and agreed-upon standard which has been defined and universally adopted. Then, characteristically it is the responsibility of one organization in a country to develop, disseminate and maintain such standards. In the dissemination of the standard, usually in the form of an artifact (i.e., standard mass), one recognizes the role of primary and secondary standards. The former is unique and the latter are carefully-made reproductions which are usually compared directly with the primary standard and are more widely disseminated. However, the hierarchy does not stop here. For more routine work, tertiary or even working or floor standards are compared indirectly with the primary standard. The relation of the standard actually used to the primary standard is embodied in the concept of traceability [14a]. The requirements for traceability are not defined by the standards organization but by the organization requiring the measurements.

Theory plays an important role in the measurement process. The theory provides a link between the observed signal and the quantity being measured. It also plays a crucial role in extrapolating a caltbration procedure from given experimental conditions to conditions that are somewhat different. Another use of theory is to relate the measured quantity to the fundamental units (e.g., basic SI units). 
Also, theory is used to define derived units and standards from the fundamental quantities, 1.e., force from mass, length and time.

It is apparent that the measurement process must be based upon standards, procedures and theory. Furthermore, the successful realization of a standard rests on a rational basis for the selection of a concept and physical embodiment. Having developed a standard an organization for maintaining and disseminating it are needed.

\subsubsection{U1trasonic NDE standards}

Nondestructive evaluation using ultrasonic techniques is clearly much more complex, for example, than mass measurements. What quantity is being measured in NDE? It certainly isn't defect size, although the information may be used to infer something about defect size. Strictly speaking, one appears to measure "ultrasonic reflectivity" $i . e .$, return energy divided by incident energy. However, even this quantity is not being measured absolutely since the incident energy is not determined; rather the return signal is compared with the signal from some more or less arbitrary reflector. Therefore, ultrasonic measurement systems can be used at present only in a strictly comparative sense. Even in the most sophisticated "imaging" system, the output is by no means an absolute image of the defect. The relationship between object and image size and shape is neither direct nor particularly clear. The measurement is not a direct dimensional measurement but a measurement of variations in acoustic impedance and consequently must rely heavily on standards for reliable qualitative and particularly quantitative interpretation.

Because of the fact that ultrasonic NDE is a comparative measurement, there is no connection to the fundamental units. Consequently, the standards that have arisen are in many respects arbitrary and in fact based on practical considerations. Thus NDE measurements made with an apparatus calibrated with one set of standards are not necessarily comparable to measurements made with the same apparatus calibrated with a different type of standard. While unnecessary diversity should be minimized, there are nonetheless reasons for the proliferation of standards due to the very wide variety of test objects and applications in ultrasonic NDE.

Although we can Imagine the possibility of calibrating an apparatus with a limited set of standards, additional standards for a specific NDE test may be required to ascertain that a given defect can be reliably detected. Consequently, a wide variety of reference blocks and product staniards (actual parts with a real or artificial defect) have appeared. It should be noted that some reference blocks have been designed so that to some degree the reference defect resembles an actual flaw and the blocks can be used for both calibration of the apparatus and "defect sizing." Even with such reference blocks, it seems that product standards will still see great use since presently there, is no 
theory enabling one to calculate flaw size from an arbitrary signal knowing the signal from a simple artificial standard.

A basic difficulty in ultrasonic NDE is that one measures one or several characteristics of a very complex signal which is affected by material properties and geometric reflectors around the defect in addition to the size, shape and orientation of the defect. Since from the analysis of such signals one would like to deduce the actual size, shape and orientation of the defect, concern about uniqueness of interpretation is warranted. Even with multiple signals such as are realized with imaging, scattering and spectral techniques, the relation between the signals and the defect is so complex that product standards will likely see continued use. Presently, however, the relationships between product standards and the more basic standards are obscure. It would appear that the measurement process yould be strengthened by providing a link between the product standard and more basic ultrasonic standards.

In sum, in ultrasonic NDE one measures relative ultrasonic reflectivity. The rather obscure relationship of this to the absolute dimensions and properties of the defect dictates that the measurement process make use of standards not only for adjusting the performance of the apparatus but also for establishing sensitivity and detectability criteria. Product standards often find use in establishing this sensitivity and detectability criteria.

\subsubsection{Ultrasonic NDE standards organizations in the U.S.}

In the United States, ultrasonic NDE standards are arrived at generally by a consensus process rather than belng issued by a central quasi-government organization as is often the practice abroad. Organizations in the U.S. such as ASTM, ASNT, and ASME issue standards documents which describe in detall measurement and calibration procedures and the use of artifacts, e.g., ultrasonic reference blocks. These organizations generally do not undertake research and development on new reference blocks but develop and document a consensus of good practice based on the experience of the participants and from the avaflable literature.

Although these standards documents formalize good current practice, for many applications current practice is insufficient to meet the demands of quantitative NDE. These demands, as embodied by imaging, scattering or spectral methods have scarcely been examined with regard to standards requirements and calibration procedures. Indeed, it is one of the objectives of this study to focus attention on such needs.

It should be noted that the National Bureau of Standards does not issue ultrasonic NDE standards documents. It does provide research and development results in the area of measurements and calfbrations and 
when warranted offers calibration services. It also contributes to consensus standards documents and provides Standard Reference Materials.

How do the roles of NBS and the consensus standards organizations differ in the area of standards and calibrations? The ASTM procedures provide, for example, a way for the operator to adjust and use an apparatus employed for NDE inspection. The role of NBS, however, is characteristically to provide a method for transferring a primary standard or measurement method from NBS to the user. This is accomplished through mechanisms such as calibration services or published methods. These procedures are often as different in detail as they are in intent.

When NBS develops a new method or standard which has potential impact on current practice 1 , as other laboratorles, must bring the information to the consensus standards organizations for their action which ultimately is realized in the form of a standards document. Of course, NBS is not the only organization that brings new developments to the field of standards and calibrations. In the area of NDE, there are many accepted and proposed procedures that have come from many laboratories. However, regardless of the origin, meritorious concept is not enough; a thorough and rigorous time consuming development is required to go from a concept to a fleld-worthy standard.

\subsection{FRAMEWORK FOR ASSESSING ULTRASONIC NDE STANDARDS}

In order to assess the many approaches that have been developed and the many more that may be proposed for ultrasonic NDE standards, a framework for dealing with these approaches is first established. In this framework, the nature of an ultrasonic flaw detection system will first be analyzed; various specific needs which standards must satisfy will then be discussed; a set of criteria for evaluating possible standards will be compiled. With this framework, a systematic search of available alternatives to satisfy the desired usage of the ultrasonic NDE standards can begin and the alternatives can be evaluated objectively for final recommendations.

\subsubsection{Nature of an ultrasonic flaw detection system}

Ultrasonic flaw detection systems may be classified according to. the nature of the interaction between the ultrasonic waves and defects in the piece under inspection. These include reflection (pulse-echo), through transmission, scattering, interference and resonance. With the exception of systems based upon resonance, ultrasonic flaw detection is a point by point measurement which relies on either scanning manually or automatically, or array type multiple probes to inspect a test object. Recently developed minicomputer based systems not only control the automatic scanning, refine the recelved signal processing and display, but also use multiple probes to collect the combined information of the interaction between ultrasonic waves and the defects. However, the 
basic functions are still the same and the basic interactions are still reflection, through transmission, scattering, etc.

Although systems for NDE based upon scattering techniques or interferometric techniques, such as acoustical holography, are being developed, pulse-echo systems are by far in widest practical use. In most common pulse-echo ultrasonic flaw detection systems, reflections (echoes) from Impedance mismatches produce indications on an oscilloscope screen in addition to the expected back-reflection pulses. The horizontal locations of the pulses on the screen represent the arrival times which in turn indicate the travel distances between indications and the probe; the helghts (amplitudes) of the defect pulse indicate the relative strength of the ultrasonic reflections. Since these indications are sensitive to instrumental conditions and settings, transducer characteristics and ultrasonic properties of the test object, calibration is necessary. Furthermore, because these indications have fewer parameters (arrival time and amplitude of the pulse-echo) than the parameters required to specify defects (location, size, shape, orientation) their quantitative interpretation is "very difficult."

Recent developments of new techniques may alleviate some of the difficulties of interpretation by refining the use of the above parameters and making use of more parameters. At the same time, these new techniques may make additional demands on system performance and make control through calibration even more crucial. For instance, instead of using merely the reflected pulse helght as the only indicator of defect size, the entire reflected pulse wave form can be analyzed. In addition to the direct reflected echo, scattered fields can also be measured with multiple transducers. The wave form of the reflected and scattered pulses and their frequency spectra contain more information that can be used to indicate the characteristics of a defect. However, a computer based system may be required to analyze the additional data. In order to make these refined techniques reproducible and rellable, many key elements of the system especially the transducers and the pulser/recelver circuits must be well characterized and properly calibrated.

\subsubsection{Uses of a standard ${ }^{5}$}

According to the terminology agreed upon by ASTM [14b], the word "standard" has two defined meanings:

a. a reference used as a basis for comparison or calibration;

b. a concept that has been established by authority, custom, or agreement to serve as a model or rule in the measurement of a quantity or the establishment of a practice or a procedure.

5See also Section 3.1 . 
While the second meaning usually establishes various documents as "standards," the first meaning clearly defines the "usage" of the standards, 1.e., a standard is used as a basis for comparison or calibration and some existing standards have served well in both roles.

Specifically, in ultrasonic flaw detection, one often uses a block or a set of blocks for the following purposes:

- to check overall equipment performance,

- to check transducer performance,

- to determine the inspection sensitivity level and 1 ts Iimitation on resolution,

- to adjust the instrument settings for range,

- to set accept-reject criteria,

- to make system performance evaluation possible in the sense that test results are reproducible from day to day, article to article, location to location, instrument to instrument and laboratory to laboratory.

- to simulate to some degree the geometry of the anticipated defect,

- to simulate to some degree the geometry of the part under inspection.

Some of these purposes, particularly the last two, are also served by the use of product standards.

Numerous reference blocks have been developed which are intended to fulfill some of the needs listed above. Because there are different test articles together with various techniques, and instruments and probes, numerous reference blocks have been developed. To some degree the optimum choice of a reference block depends upon the intended usage so that the question of which block is best can be answered completely only when this use is fully defined. Nonetheless, some blocks possess greater versatility than others; see [12]. It may be interesting to note that it was the search for a versatile and simple "standard reference" that prompted the adoption of the flat bottomed hole (FBH) [1]. It is worth emphasizing that the intended use of a block, particularly a proposed block, should be carefully specified since blocks are frequently most useful for rather specific applications.

\subsubsection{Criteria for evaluating possible standards}

Given that there are candidate blocks which meet given requirements it is necessary to evaluate their relative potential. The following is a list of criteria which may be useful in evaluating various existing and proposed ultrasonic standards. For specific applications, other points may have to be considered in addition to the criteria listed below. The 1tems are not rank ordered since their importance may depend on the specific requirements. 
a. Functional adequacy. Will the standards rellably and adequately accomplish their intended use?

b. Reproductbllity of test results. Can the test results be reproduced not only within a given organization but also among different laboratorles?

c. Ease of duplication. Can the standards be fabricated at different laboratories and at a reasonable cost?

d. U1timate cost of standardization. How much will it cost the users to implement an adequate standardization program? Will such a program be cost effective?

e. Versatility in providing simulated situations. How many reference standards are needed to carry out calibration of varfous instruments for different test objects?

f. Correlation with real defects. Can real defects be quantitatively compared with the reference standards?

g. Avallability of independent examinations. Are there independent techniques (such as radiographic techniques) to verify the standards?

h. Compatibility with existing standards. Is the proposed standard compatible with or traceable to existing standards?

1. Avallability of a theoretical basis. Is there a theoretical model to establish the standards and to verify and extrapolate the results?

j. Ease of automation. How readily can the standard system be automated to reduce rellance on operator performance?

k. Ease of implementation. How easy is it for an operator to use the standard?

1. Ease of modification to satisfy future needs. How readily can the standard be adapted to meet future requirements?

3.3. AN APPROACH TO A SYSTEMATIC EXAMINATION OF ULTRASONIC REFERENCE BLOCKS

\subsubsection{Introduction}

Numerous reference blocks have been used in NDE for the callbration of ultrasonic flaw detection systems. These blocks, varying in shape 
and material, are used primarily as a field standard but also as a laboratory standard to check the ultrasonic equipment performance and to make test results reproducible. In the United States, sets of blocks with flat bottom holes (FBH) are recommended by ASTM as a general purpose reference standard for use in, for example: (a) checking performance of ultrasonic testing equipment, and (b) standardization and control of ultrasonic tests of metallic products using pulsed longitudinal waves introduced into test materials either by the direct contact method or by the immersion method.

Several criticisms have been raised regarding the FBH standard. The most prevalent is of the variability of these blocks; however, recent developments provide a mechanism for solving these problems $[11,15]$. Another criticism regards their suitability for providing an accept-reject criteria. A further criticism is that they are difficult to apply outside, of the area of qualitative inspection and process control. Finally, it has been stated that the back scattered field of the FBH lacks a theoretical basis. However, this is clearly not the case since the short wave length limit for back scattering has been known for a long time. Moreover, recent theoretical work deals with a method for improving the earlier results by taking into account the diffraction correction due to the edges [16].

Many new blocks have been proposed and while it is possible to evaluate each proposed design separately, one must realize that the selection process is very difficult because of the complex requirements and infinite variations in block design. To this end, instead of comparing and evaluating various existing and proposed block designs, we systematically review generic design parameters and examine how these parameters effect the block's function. A very limited experimental study was conducted to supplement our conceptual analysis; see Appendix B.

\subsubsection{Analysis of block design}

Broadly speaking, a simple block consists of three generic components: material, reflector geometry, outer geometry. Perhaps the simplest example embodying these generic ingredients is a rectangular aluminum block in which the reflector corresponds to the outside geometry, namely a back planar surface. At the other end of the scale of complexity is, perhaps, a landing gear which has a very complicated outer geometry and contains a fatigue crack as a reflector.

Another example of complexity is compound blocks made of more than one material and having multiple facets as reflectors. An example is the IIW block which is made of plastic and metal and has as its reflector a circular curved surface, a side drilled hole, a rectangular notch, etc; see [12]. 
In what follows, we separately analyze the three ingredients of a block and study possible options and implications.

\section{Material}

Although an obvious candidate for a block material is that of the test article, there are at least two reasons for considering another cholce. First, an ultrasonic flaw detection system may be used for a varlety of materials; 1t may not be practical to use a different standard for each material. Secondly, the varlations of ultrasonic properties (wave speed, acoustic impedance and attenuation characteristics) among test articles made of nominally the same material may be large and the selection of one particular material may still deviate somewhat from the actual test articles. Consequently, the cholce of materials for a standard could be based upon the following factors:

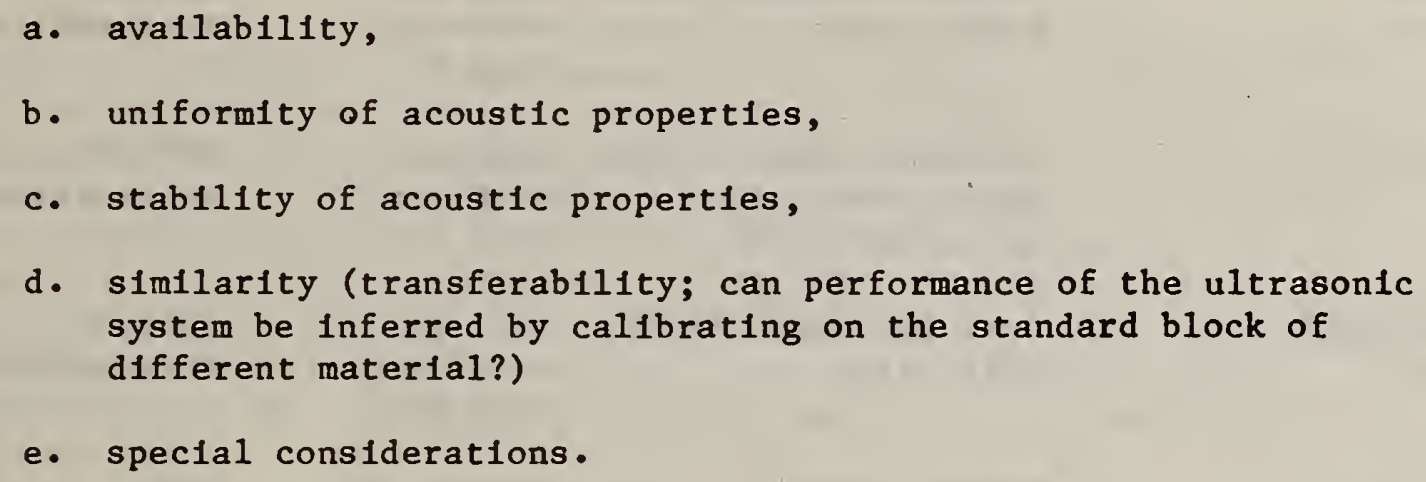
system be inferred by calibrating on the standard block of different material?)

e. speclal considerations.

Table 1 lists some possible materials. Note that liquids such as water and viscous flulds are candidates and water has been used in the calibration process, although no one has suggested 11terally using water as a possible block. However, it has many advantages:
a. easily ava1lable, stable and unfform;
b. propagating path length in this medium can be changed easily;
c. various geometric reflectors can be implemented as "solid inclusions"; d. fleld observation can be 1 mplemented - beam profile can be
easily obtained. 
Table 1. Comparison of matertals for possible standards.

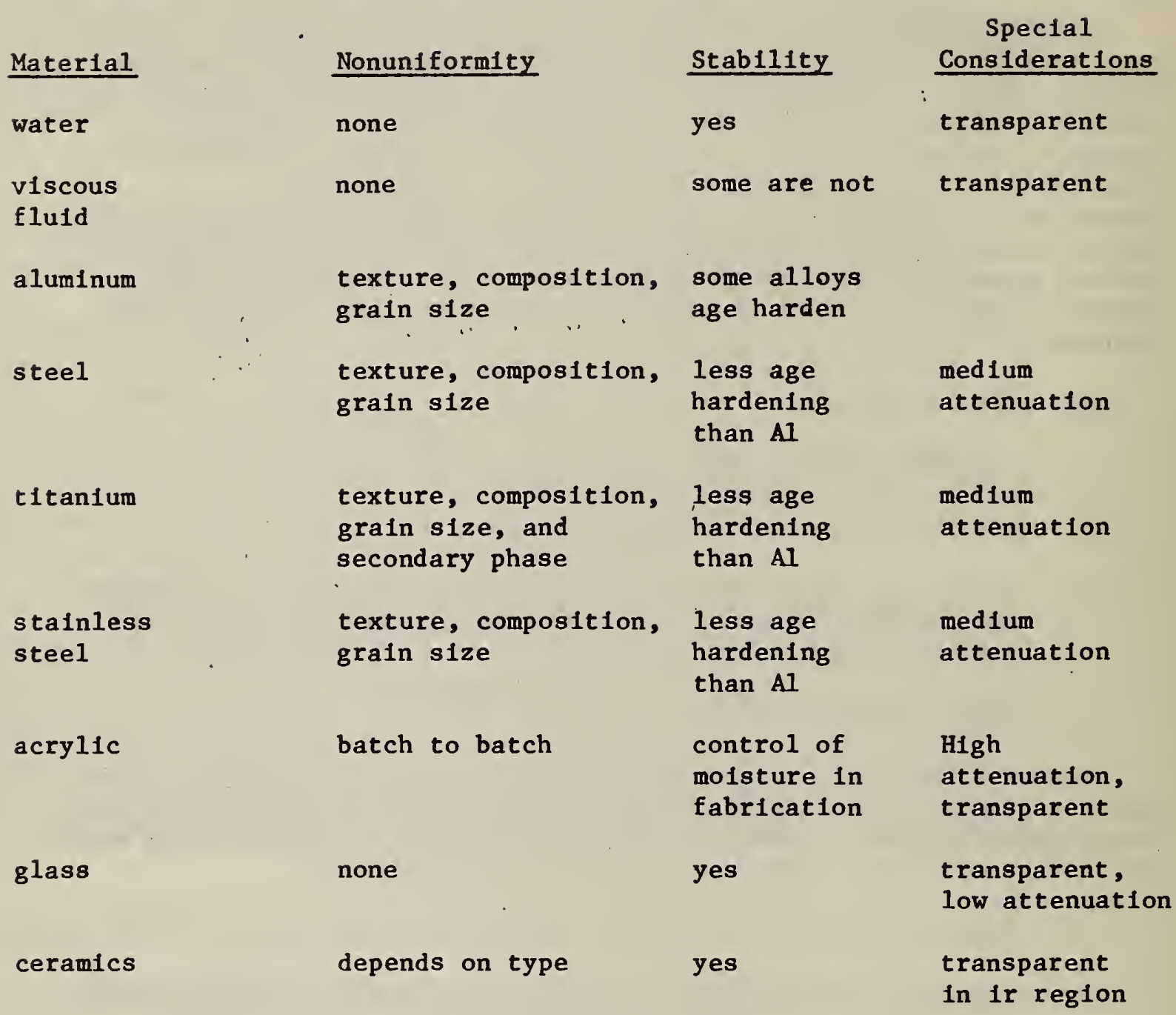

The disadvantage of using a liquid is that for many flaw detection problems there is a lack of similarity between the liquid and the test article. Furthermore, 11quids generally cannot be used to simulate shear wave techniques. Finally, the effect of transducer coupling to a solid is not simulated by a liquid test object. However, an important advantage of a liquid as a "block materlal" is that 1t permits direct inspection of the "flaw" and a direct visualization or mapping of the transducer field.

The acoustic field in glasses and acrylics can also be probed by making use of photoelastic visualization techniques [17]. Although, ceramics are opaque they are also transparent in selected portions of 
the infrared region where the photoelastic effect could be used for visualization. It is interesting to note that in such materials a point by point determination of the internal field has not been realized but may be possible. See [18] for a description of such a realization in the transparent case.

The selection of materials also points out several existing problems of the ultrasonic flaw detection system.

1. How does a transducer behave when it is coupled to different solids? Is it possible to infer the transducer's behavior from one solid to another?

ii. How can the ultrasonic properties of a solid be characterized? If these properties are properly measured, w111 they allow one to answer question i?

In principle there are no scientific problems in characterizing the ultrasonic properties of the commonly used structural materials. It would be possible to develop a data base on velocity, attenuation and impedance as a function of frequency for these materials. However, gfven knowledge of these material properties, couplant and transducer characteristics, can the calibration of a flaw detection system be transferred from one material to another. This would seem to be possible particularily if use is made of current theories. However, currently available data and current practice still require direct calibration of the system on a reference made of the same material as the test item.

\section{Different reflector geometries.}

A reflector provides a reference signal for adjusting ultrasonic systems and also, depending on the objectives of the test, for "flaw characterization." But, because of the complexity of real flaws, the reflector in a reference block can only partially simulate a real flaw. In present practice reflectors are often used to provide a reference for arrival time to indicate flaw depth and a reference for reflection strength to "indicate" flaw size. It is also important to obtain information on flaw orientation and type. It is possible that this additional information may be obtained from the analysis of the scattered field and spectral response. Imaging is an approach that may provide all this information but nevertheless will have to rely on reference blocks to some extent.

Reflector geometries that are in use or have been proposed include planar and curved surfaces, steps, notches, FBH reflectors, cylindrical reflectors, spheres, ellipsoids and disks, many of these both as voids or inclusions. The choice of reflector geometry is a subject of some controversy. Although this matter will not be settled here, we note some of the current views. Spheres and side drilled holes are said to 
more closely represent the bulk of the defecss found in welds. However, planar reflectors such as an FBH are said to better represent the more critical weld flaw - a crack. The scattering spheres and ellipsoids have a theoretical basis, although theories are also available for discs and cylinders. Side drilled holes are preferred by some because they are said to provide a reference not only for longitudinal but also for angle beam testing. The $\mathrm{FBH}$ is said to well represent lamellar defects, a more common defect in plate material. Spheres also seem to represent well the small voids which may occur in ceramics. Notches of various types ( $V, U, E D M)$ are often used to represent surface cracks.

A somewhat different and exciting approach in artificial reflectors is the use of manufactured fatigue cracks [19] . Obviously, such a reference block would offer simulation advantages over other reflectors. for many tests but is more difficult to manufacture and to theoretically describe.

\section{Outer geometry.}

The outer geometry: provides for various metal distances between the transducer and the reflector, permits varying the angle of incidence, defines the sound path to the reflector (e.g. the reflector may be accessible by longitudinal beams but not angle beams), and simulates the geometry of the test item. In practice a variety of outer geometries have been proposed or are in use.

\subsubsection{An example of the critique of a proposed standard}

An important part of the analysis of the improvement of the system of ultrasonic standards is the critique of current and proposed standards. Here we give an example of the type of analysis that should go into the evaluation of ultrasonic standards. The example may be more important in the demonstration of the methodology than in the particular conclusions reached. The example chosen is the proposed use of the scattered field from a spherical void in a metallic block used in a goniometer (see, for example, [19A]). This choice was made because this proposal has benefited from a large theoretical and experimental effort. This analysis may change, however, on the basis of additional considerations or developments.

The standard we consider here consists of:

- A diffusion-bonded titanium polyhedron or sphere with a spherical cavity as the reference reflector. The two halves of the block each containing a hemispherical cavity are diffusion bonded together.

- A calibration scheme based on: (a) procedure derived from radar antenna calibrations which relates the received signal to the transmitted signal by an equation which is a product of 
the transfer functions of the transmitter, recelver, thansmission media, transducer and scatterer; and (b) a theoretical description of the scattered field of a spherical reflector. It has been proposed that if the media characteristics are known, use of the theoretical field will give the transfer function for the transducer.

Intended uses.

Although this approach has been presented as a more or less general one intended to replace, for example, flat-bottomed-hole blocks, the specifics of its intended use have not been made completely clear. Nonetheless, we here interpret intended uses in terms of published references [19a-19c] and personal communications. By reference or implication we also perceive that the intended application is for general systems, at least including scattering and pulse echo systems,

a. to check overall equipment performance - yes,

b. to check transducer performance - yes,

c. to determine inspection sensitivity - yes,

d. to adjust instrument for range - not clear,

e. to set accept-reject criterla - not clear,

f. to provide system reproducibility - yes,

g. to simulate the geometry of the defect - perhaps,

h. to simulate the geometry of the part - no.

\section{Criteria.}

Based on the information avallable, we discuss the proposal in terms of the criterla for evaluating standards given in Section 3.2.3.

a. Functional adequacy. A spherical reflector may be useful for pulse-echo systems (see for example ASTM E-127 and [20]). However, its use in a calibration system which is configured in a scattering mode with separate transmit and recelve transducers seems most approprlate for test systems also configured in a scattering mode. In this case the full benefit of making use of the theoretically predictable changes in intensity with angle can be affected.

b. Reproducibility of test results. An independent study of one of the titanium blocks ${ }^{6}$ indicated a lack of agreement with published data. However, this is not surprising since a great

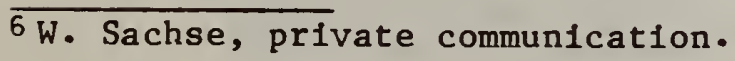


deal of work is usually required not only on the artifact but on the measurement procedure and signal interpretation before even modest reproducibility can be achieved as discussed in reference [11].

c. Ease of duplication. Here, as with any other block, material unfformity is a potential problem, one that can usually be overcome with elther considerable care or through initial selection. Given a supply of uniform material, it would seem that the machining of accurate hemispheres and subsequent diffusion bonding is a capability that is not yet widely avallable. It seems that at least at present such a block would be somewhat more expensive than some other alternatives.

d. Ultimate cost of standardization. The cost of implementing a total change from currently accepted reference system to any new block(s) for all the general flaw detection systems would in fact be rather large. If the change were intended only for a class of systems (such as scattering systems) the cost would be considerably less. Therefore, the cost/benefit ratio depends heavily on the range of systems for which replacements is considered.

e. Versatility in providing simulated situations. It would appear that by making use of the dynamic range of the scatterer for setting gain or determining linearity, significantly fewer blocks would be required in the proposed system than in the FBH system. However, to realize this advantage, the ratio of the radius of the sphere to the wavelength of the ultrasound (In the material) must be chosen properly. Even so, the dynamic range is compressed significantly if a broad band source is used owing to averaging over the range of frequencies. A configuration we can concelve which has the advantage of large dynamic range and equally applicable to pulse echo systems is a sphere located asymmetrically in a polygonal plate to give different metal-travel-distances.

f. Correlation with real defects. Generally, artificlal defects do not simulate real flaws of concern for structural integrity, although some geometries simulate certain types of defects better than others. For example, in weld inspection it is generally agreed that spheres (or side-drilled holes) better simulate the types of discontinuities most of ten found such as porosity and inclusions. However, many also agree that a FBH somewhat more closely resembles the defects of greatest interest, $1 . e$. cracks. To refterate, neither reflector does the simulation job adequately; this again suggests additional interest in manufactured fatigue cracks (see Section 4.22 and [19]). For some inspection applications 
the sensitivity required and the defects expected seem strongly to favor spherical or hemispherical reflectors, e.g. very high sensitivity inspection of ceramics for porosity [20]. However, for the bulk of ultrasonic flaw measurements the size sphere required to give the proper signal strength makes their use cumbersome.

g. Avallability of independent examination. Prior to fabrication by diffusion bonding, the reflector geometry is amenable to various kinds of inspection. However after fabrication independent inspection must be made by radiography. This is in contrast to say side-drilled holes which can be optically inspected even after completion. This consideration of post fabrication inspection also suggests the use of transparent material, see Appendix B.

h. Compatibility with existing standards. Because the proposed system is based on scattering and the use of two transducers, it is not automatically compatible with existing standards. It would appear, however, that it could be made traceable. With respect to back reflection, spherical reflectors are already compatible with existing standards since spheres are the basic standard in e.g., ASTM E-127.

1. Avallability of a theoretical basis. For the short wavelength region, 1.e., the regime of geometrical optics, a theoretical basis is avallable for many reflectors. However, outs lde this region the theory for the proposed system has been extensively developed [21-24, and the references sited therein]. This theory would make $1 \mathrm{t}$ possible to verify and extrapolate measurements and also would provide the theoretical base often desired for a primary standard.

j. Ease of automation. No obvious advantage for automation is apparent.

k. Ease of 1mplementation. There seems to be no obvious advantage to the operator with this system, although it could result in a less bulky system.

1. Ease of modification to satisfy future needs. Without specific future requirements in mind, it is difficult to evaluate this aspect. For lmaging systems, for example, the proposal seems to have no clear advantage. However, for requirements leading to the use of say elliptical rather than spherical reflectors, the concepts of the proposed system stay mainly intact which would be an advantage.

In conclusion, we see no special advantage in replacing current standards for pulse-echo systems with the gonlometer-sphere proposal. 
However, for scattering systems (and possibly for systems using transform methods) the proposed system seems to offer some clear advantages over presently accepted systems.

\subsection{THE CHARACTERIZATION OF ULTRASONIC TRANSDUCERS FOR NDE}

In this section we deal with the standardization problems associated with transducers in ultrasonic measurement systems. The need for dealing with the variability of ultrasonic measurement due to transducer characteristics have been reemphasized frequently in the open 1iterature; see for example [25-27]. Two basic questions seem to arise:

1. Which characteristics of the transducer must be measured, controlled or compensated for at a given level of standardization or in a given application?

2. How can these measurements be made, keeping in mind the many types of transducers available and under development and the large number of applications?

In trying to address these questions and arrive at some partial answers we have relied, in the main, on the extensive reports of Sachse and Hsu [14], Miller and Eitzen [28] and Smith, Teller and Swanson [29]. Reference [14] was an outgrowth of this effort and grew to such large proportions that it warranted separate publication.

Here we briefly sketch the contents of reference [14]. This work, which is meant to be rather complete, deals with the analysis of a transducer operating as a source and a receiver, reviews the large variety of transducer types, reviews acousto-electric techniques for deliberately modifying the transducer in send or receive mode and discusses transducer characterization. It is clear that quite general characterization techniques must be developed or one will be forced into developing many different techniques due to the many transducer types and applications. Three levels of transducer characterizations are given:

1. Complete characterization. This procedure which, in principle, determines all the parameters of a linear, one-dimensional transducer, fully characterizes it, so that all of the questions pertaining to the transduction process can be answered. Here the transduction is absolutely characterized independently of the test medium or generator/recelver electronic circuitry. This involves the measurement of the frequency-dependent complex functions which comprise the transduction matrix associated with a transducer.

2. Partial Characterization. When efther the electronic instrumentation or the test media are flxed, the transduction process can be represented by a transfer function for the transducer acting either as a source or a receiver. This simplification from a 
transduction matrix to a transfer function relles on a specification of the media or electronics associated with the application. A variety of rethods are avallable or being developed, including the use of a known source function, the use of a known scatterer and the use of impedance measurements.

3. Transducer Checks. In many ultrasonic measurement applications, the absolute calibration of a transducer (as in 1 and 2 above) may not be necessary. What is deemed sufficlent are methods for checking to see if the operation is as expected or is unchanged from a previous calibration. The parameters so determined may include frequency response, loop sensitivity, electrical impedance and beam characteristics.

Various methods for mapping transducer sound flelds are described in a separate section of [14].

In the final pages, reference is made to the serlous assumptions required for the "complete characterlzation" referred to in 1 above and the need for correlating measured field parameters with electrical excltation parameters.

We have a number of comments regarding the status of standardization as reflected by this work. Although the "complete characterization" gives all of the transduction parameters, the connection to final performance in field applications is not clear. Certainly, such a complete characterization is necessary for understanding performance and helpful for design specifications but in itself knowledge of the transduction matrix is not sufficient to predict or verify field performance. We note, in particular, that the onedimensional assumption makes the connection to field performance rather difficult. It seems to us that the "partial characterization" utilizing a transfer function may be a practical way of specifying transducer performance which may correlate more easily with performance in NDE applications. The necessary specification of material or electronics may not be overly severe since certain commonality in many applications exists.

The "transducer checks" involve the measurement of a variety of acoustic or electrical parameters, many of these making use of blocks. ${ }^{7}$ Taken overall, the three levels of characterization described in [14] represent a considered account which deserves additional study.

Methods for mapping transducer sound fields range from qualitative techniques for observing the projection of a beam pattern to complete determinations of the 3-D fleld by planar scanning methods [14]. With

For a detalled account of the accepted methods of using blocks see the associated work by S. Golan [12]. 
regard to the latter, it has been shown rigorously that a scan of phase and amplitude in one plane is sufficient to reconstruct the entire sound field in a relatively fast and economical way using modern computational methods. It should be emphasized that a complete characterization of a transducer utilizing the transduction matrix as in (1) above does not specify the actual fleld. For many applications the beam shape, direction, magnitude of side lobes, symmetry and uniformity are all important but so far must be determined through beam measurements. Particularly in quantitative measurements the character and detail of the interrogating energy must be known or verified.

We next summarize the work by Smith, Teller, and Swanson [29]. The objective of this work was to characterize a number of commerclal ultrasonic transducers of various types and to examine the correlation of transducer characteristics with their performance in detecting flaws of several types. The motivation for the work is the wide variation in the performance of ultrasonic transducers $[25,26]$. Its objective is the correlation of the effect of these parameters with the rellability of ultrasonic inspection procedures for small fatigue cracks. The scope of the work included the derivation of 17 descriptive transducer parameters from measured characteristics for 23 transducers. Flaw detection performance was limited to longitudinal-immersion examination of an FBH standard, an elox notch and two fatigue cracks and was found to be highly variable. The results of the investigation showed good correlation between "loop sensitivity" ${ }^{8}$ and the ability to detect flaws. Other parameters which appear to have reasonable correlation with flaw detectability include center frequency, beamwidth, spectral shape and side lobes. The authors conclude that prediction of the flaw detection performance of individual transducers based on measurable parameters appears to be a reasonable goal.

We agree with the caveats given in the conclusions to this report: The sample size could be made statistically more valid; the restriction to longitudinal immersion conditions is an important one; and the goal of specifying parameters to predict flaw detectability and the certification of transducers (for some applications) based on the parameters appears to be reasonable.

However, while it seems that loop sensitivity can be easily measured and specifled, it does not appear that the work yet provides a preliminary criterion for certification of transducers for service. Although a strong correlation between transducer loop sensitivity and flaw detection performance was demonstrated, the results may have been influenced by the use of low frequency transducers which also had low loop sensitivity. Further work along these lines would be desirable. If further investigations show that the loop sensitivity parameter is a good predictor of transducer performance for flaw detection, then it

${ }^{8}$ Loop sensitivity is related to the transducer send/receive sensitivity but the exact specification depends on the method of measurement. 
would also be important to determine the more basic quantities on which this depends. It then may be possible to eliminate redundant transducer tests and at the same time to indicate to transducer manufacturers the precise parameters that need to be controlled. The important point about the study is the emphasis it gives on determining those transducer characteristics upon which its performance in an NDE detection mode depend. We regard such specification as essential for improving NDE performance in an efficient and cost effective manner.

For the more difficult NDE mode of quantitative flaw measurement (contrasted with the detection mode discussed above) a similar correlation approach would likely also be helpful. (In this regard reference [27] presents a limited study demonstrating this.) For a full correlation of transducer variables with performance for quantitative NDE the 11st of variables may grow somewhat It is reemphasized that the pragmatic solution obtained by correlation studies should be supplemented by an understanding of the basic variables in order to avold over-specification. Knowledge of these basic variables also provides the transducer manufacturers with information needed for design and quality control.

A rather extensive transducer characterization program under way at NBS [28] deals with, in part, methods for determining absolute total power versus frequency, time-averaged power and complete beam patterns (cw) into a water load. This part of the program is nearly complete. The physical theory applicable to each method provides the basis for analyzing the measurement uncertainties. In addition to the work described in [28], work on field methods for scanning transducers [30], on criteria for specifying transducer parameters [27] and possible methods for measuring flelds in solids [17] are being pursued. There is also considerable interest in developing laboratory measurements for pulsed excitation and for angle beam transducers. The emphasis has been on developing primary measurement methods and services but work is also devoted to the development of field techniques to be carried out by the user.

Thus far in the discussion the transducer type has not been specifled. Although the most common transducers in NDE have used plezoelectric elements there has been a growing use of electromagnetic acoustic transducers (EMAT). One of the principle advantages of this transducer is that it is noncontacting and thus eliminates dependence on acoustic coupling efficlency and allows for use in severe environments. There is a dependence on the gap between the coil and specimen but this can be minimized by proper design. Further, EMATs may have some practical advantages in generating polarized waves. From the point of view of standardization, EMATs could play a valuable role in characterizing other transducers insofar as the measurements are reproducible and the transduction can be modeled. However, an 
electrostatic transducer would appear to have these advantages to even a greater degree. 9

Based on the literature there are many methods of measuring something about transducers. In many cases, what is being measured and to what accuracy is often unclear. Also many methods are limited to water loads and $\mathrm{cw}$ excitation. It appears that the basic transducer principles are clear, although additional theoretical work in some areas is needed. More important, though, is a more complete determination of the most crucial performance parameters (possibly a more comprehensive study of the type in [29]) and, with quantitative NDE in mind, their accuracy. Once this is known an effective measurement system for transducers can be established; many of the necessary techniques are essentially at hand.

\subsection{STANDARDS IMPLICATIONS OF NEW ULTRASONIC NDE TECHNIQUES}

Our discussions on calibrations and standards thus far have been mostly independent of whether the measurement system is a conventional or an emerging one; however, the conventional systems have influenced our discussion. In this section we emphasize the possible effects of the emerging systems in terms of standards and calibrations. The question of standards implications of new techniques are also raised in sections $4.1 .1,4.1 .2$ and 4.1 .6 .

Possibly, the most important developments have been spectrum analysis, time delay techniques, several types of imaging systems, adaptive learning networks and special transducers. In order to improve signal-to-noise ratio and resolution, signal processing using computers and microprocessors have been introduced into ultrasonic systems.

In addition to the reflectivity phenomena utilized in the conventional pulse-echo technique, other phenomena of interaction between the acoustic field and the flaw, such as scattering, diffraction and interference have been studied. Many basic and experimental studies have been carried out and various sophisticated laboratory systems have been developed. There is, however, still a wide gap between the theoretical and laboratory studies and applied NDE. Many of the new developments are based upon simplified, idealized models for the flaws and idealized experimental conditions rather than on real conditions and flaws which are far more complicated. Unfortunately, the bridge between model and real conditions can not easily be crossed. It is hard to predict which of the current developments will turn into practical, quantitative NDE tools. The ideal ultrasonic technique which will determine the absolute location, size, orientation, shape and stress

${ }^{9}$ Current work at NBS makes use of a standard source and an electrostatic transducer as a recelver to a very high absolute accuracy. Report in progress. 
field of a flaw is a distant goal and requires significant advances in the state of the art. To further expect this ideal system to be independent of calibration and standardization does not seem to be practical.

Each new development offers additional information on flaw characterization, but also creates new and more complex problems of interpretation and standardization. A few examples will demonstrate what new calibration and standardization problems might develop.

The transducer is the key of each ultrasonic system and its performance is a primary factor in the overall performance of the system. It is difficult to produce piezoelectric transducers with preplanned, reproductble characteristics and the performance characteristic of each transducer must be individually checked. This is one of the main reasons why no primary source of ultrasonic standards exists and why a universal standard of comparability is difficult to establish. In the conventional pulse-echo systems single element transducers are usually used. Standardization and characterization of these has not yet satisfactorily been accomplished.

In many of the new systems, multi-element transducer arrays are used. For these the problem of standardization and characterization is much more complex. Differences between characteristics of the individual elements and cross-talk between elements are problems which do not exist in the production and characterization of single element transducers. Due to the large number of parameters needed to characterize particularly complex transducers, it seems that computer analysis of the data for characterization will be required. Some work on a minimum data set required for transducer characterization has been done and measurement systems are being developed [28]. Additional work in this area is needed.

Imaging systems standards w111 be needed for overall system evaluation and for flaw characterization. The parameters which determine the quality of the image in an imaging ultrasonic system are sensitivity and resolution. To verify those parameters special blocks are required. An aluminum alloy $1100-F$ test block designed for checking sensitivity and lateral resolution of a scanning acoustical holographic system is described in [31]. These blocks, however, are not very useful for the interpretation of the reconstructed 1mage. Real flaws are much more complex in their geometries and scattering properties. Consequently, for correct interpretation the image should be compared to reference Images obtained with known types of flaws such as cracks, pores, incomplete weld fusion, etc [32].

Another example which will demonstrate the complexity of standardization and calibration of the new systems is the use of test specimens in an adaptive learning network (ALN). The system is "taught" to recognize the signature of a specific family of flaws in a determined 
environment and to estimate the size and orientation of the flaws. The "teaching" process is accomplished with a set of reference reflectors of the same family to be tested, introduced in an environment (material and geometry) identical to the real environment. This will best be demonstrated by a case example [33]. In order to size fatigue cracks in fastener holes in aluminum plates, sixteen test specimens were used to "teach" the network. The specimens were made of the same material, had the same geometry as the real structure and contained fatigue cracks in the fastener holes of the type expected in the structure. After the "teaching" process, the system was "smart" enough to deal with this specific problem, but for a different type of flaw or a different environment the network has to be "trained" again using a different set of test specimens to simulate the new situation. This is a highly "specific" (product oriented) approach to standardization (see [12]). Moreover, the process of calibration for the ALN system is more complex than for a conventional pulse-echo system because multi-parameter response has to be determined, while in the conventional system the only parameter to be considered is echo amplitude. Additional parameters such as time delay, frequency spectrum, power density spectrum, autocorrelation function and the Influence of any combination of these have to be considered.

In the last decade attempts have also been made to develop computer automated ultrasonic inspection systems [34, 35]. These have been developed to make tests more reproducible and more reliable, to reduce inspection time and to minimize operator intervention in calibration, setup and data interpretation. In order to evaluate and standardize the system special test blocks are ut1lized. Reference [34] describes Air Force Materials Laboratory Test Block No. 1 for evaluation of a computer automated system. Even the use of a sophisticated computerized system must rely on reference standards to evaluate system performance.

Those examples show that the standardization problems of the new methods are far more complex than those of the conventional pulse-echo technique. 


\section{SECTION IV}

\section{OUTPUTS OF THIS STUDY}

\subsection{KEY ISSUES}

This section contains many of the central questions regarding improved quantitative ultrasonic NDE and the role of standards. Many of the issues were drawn from discussions in the Workshop on U1trasonic Nondestructive Evaluation Standards held at NBS, October 17-18, 1977, expressly for this purpose. Others are from conversations with NDE practitioners and those interested in advancing NDE. The discussion of the issues forms a basis for guiding our recommendations for further effort on improved ultrasonic $\mathrm{NDE}$; these recommendations are presented in section 4.2 .

\subsubsection{What are the standards requirements for quantitative NDE?}

One can, in general, distinguish between two NDE functions: a qualitative and a quantitative assessment of material or structural defects. In quantitative NDE one tries to provide information needed to determine the absolute integrity of the piece. In order to use the tool of fracture mechanics, it is necessary to determine one or all of the features of a flaw such as size, shape, orientation, composition, etc. Although such a goal is unrealistic in the light of current practice, new developments including imaging systems and adaptive learning techniques seem to make such a goal closer to reality. However, we can only repeat here what has been mentioned elsewhere in this report; see, for example, 3.5. First, the fact that one "sees" an image of a defect by no means implies that the vision is free of distortion. It seems clear that a set of artifacts will have to be used to ensure that the apparent size, shape, orientation and location are correct. One must also deal with the inherent difficulties of using a two-dimensional image to assess three dimensional attributes such as shape and orientation, although this problem may be solved in part by future developments in 3-D imaging. In addition, it is clear that resolution (range, azimuthal, front surface) must be determined. Thus, as mentioned previously the standards requirements for quantitative NDE systems appear to be more complex than for the present pulse-echo methods.

4.1.2. What is the impact of computer-based systems and advanced signal processing on standards requirements?

From a somewhat extreme point of view the question has been sometimes asked "With smart systems are standards necessary?" However, a computer in and of itself does not eliminate the need for standards and calibrations. It can, however, assist in performing, recording and evaluating the more difficult calibrations that will undoubtedly be 
necessary in the use of the more complex systems to be used in quantitative NDE.

\subsubsection{Hierarchy of standards}

The National Bureau of Standards traditionally provides traceability of standards at a national level and maintains primary standards. When necessary to disseminate or gain access to the national standards, calibration, measurement services and standard reference materials are provided. Often, secondary standards which have a defined relationship to the primary standards are used as laboratory standards in a given organization. In addition, there are field standards or product standards which are used in connection with the actual measurements. Consensus organizations such as ASTM generally focus on procedural standards, secondary or fleld standards and their use in calibration. Thus the spectrum of standards includes primary standards, secondary standards, fleld standards, calibrations and procedural standards.

\subsubsection{Is there a "super" block that does everything?}

Many blocks have been developed or proposed (see [12], section 3.3 and Appendix B) for use in the calibration and adjustment of several aspects of the measuring system. In some cases the blocks in conjunction with a standards document are capable of a rather complete system calibration. However, a block which could be used to determine system function and adjustment, characterize the radiated ultrasonic field, assure repeatability, provide for interpretation of complex geometries, assure resolution, provide for assessment of shape, size, and orientation, is not application-specific and is theoretically describable does not now exist, nor is 1 t obvious how it could be realized. However, some of these attributes are or could be embodied in a reference block. A number of reflectors are theoretically describable including spheres, cylinders, ellipses and flat-bottom-holes. Blocks which are less application-specific in the sense that they are material independent could be developed. For example, fused quartz would provide a low attenuation, amorphous, transparent reference material which has desirable attributes independent of the internal reflector geometry. It is apparent that a "super" block does not exist but that a carefully designed system of blocks including product standards is an appropriate goal if the performances of these blocks are defined and related to each other.

\subsubsection{Overall versus separate component calibration.}

We imagine that there is available a product standard that has precisely the size and shape flaw we want to detect. Since the general requirement is to detect this size flaw or greater, 1t would appear that by merely adjusting the response to this flaw the problem of calibration has been overcome by an overall system calibration. However, because 
the system may now be in a nonlinear regime, there may be very little discrimination between flaws of different sizes. Independent of this, incompatible bandwidths among subsystems may frustrate, for example, Fourler analysis of the recelved signal. In these circumstances it will be necessary to analyze subsystem performance to find the cause. Also, if the system performance degrades or inadequate performance is apparent in the first place, it will be necessary to determine the nonfunctioning parts of the system.

In practice, proper system performance is often achieved by trial and error with avallable subcomponents, e.g. transducers. However, when an appropriate one is located, a basis for obtaining coples of this component is required. This basis is provided, of course, by measuring the appropriate component characteristics. Further, when tests are performed under written agreement, the procedure often dictates required characteristics such as test frequency which cannot be predicted or assured by conventional calibration of the overall system. Finally, it seems clear that with more advanced and complex systems which w111 interrogate and process data in a more sophisticated way, the performance of subsystems and their interdependence are even more critical and their characteristics will have to be carefully specified and determined.

If system subcomponents are callbrated separately, do we need any reference blocks? At the laboratory level the Individual component characteristics may be determined at least on recelpt of equipment and at the time of some malfunction. In field use the equipment must be checked frequently and with little ancilliary equipment. For this, reference blocks provide a useful way to adjust and check overall performance. However, development of an internal test set as part of the NDE apparatus may relleve some of the pressure on reference blocks to do more than they reasonably can.

In summary, it is not a question of either subcomponent or system checks; rather, both seem to be necessary albeit at different places in the hierarchy of standards and calibrations.

4.1.6. Why be concerned about trying to 1mprove current standards for pulse echo techniques when better techniques are around the corner?

It seems obvious to us that because of the relative simplicity of the pulse echo techniques that they will be widely used in some applications for many years to come regardless of the advent of better (quantitative) techniques. Consequently, it is necessary to make these techniques more reliable and more quantitative through improved

standards and calibration procedures. When the 1mproved techniques are developed to the point where they recelve wide acceptance, they will require standards of their own. However, these "new" standards in many cases may be the old standards used in a different way or will be some rather direct derivative of the old standards. This w111, in part, 
arise because many of the new techniques are pulse echo systems but with markedly improved display or signal processing. In short, improving standards for current pulse echo systems does not represent wasted effort not only because more quantitative methods will not obsolete the more qualitative methods but also because these improved standards w11l quite likely find use in the improved systems.

\subsubsection{What are the tolerances on reference blocks and transducers that are really required?}

To clarify the nature of this problem, we cite several examples involving the question of tolerances. In some consensus documents the tolerance on transducer probe normallty with respect to the part being inspected is specified on the basis of convenient practice. It would be preferable to base this tolerance on the effect of misalignment on signal amplitude. The user community might find the effect of misalignment intolerable if it were known. It also might find the cost of a smaller tolerance distasteful. Another consensus standard specified a tolerance on center frequency of transducers that is percelved as being so stringent that virtually all manufacturers refuse to supply transducers based on that specification. Here again the effect of meeting a tolerance requirement in terms of detectability or accept/reject criteria is not known so that a rational decision based on effect versus requirement and cost cannot be made. Clearly the data for such decisions should be developed.

4.1.8. What are the requirements for transducer calibration?

It appears that transducer manufacturers and large laboratories may find it necessary to have some transducers that are very carefully characterized as laboratory standards. Also, it would seem appropriate to determine in detall all of the characteristics when developing a new transducer. The large number of transducer types (focused, wide band, array, contact, plezo, EMAT) will require an extremely general technique or techniques. The fleld test laboratory, on the other hand, may find it necessary to determine fewer parameters, such as center frequency, bandwidth and some aspects of the beam pattern. In field use it may only be necessary to determine that the characteristics previously established have not substantlally changed. In short, the extent or completeness of transducer characterization depends heavily on the application.

It is constructive to consider the following example because at first glance it would appear that in this case transducer calibration is unnecessary. In systems making use of Fourler analysis of recelved signals where this signal may be considered a product of the reflector and subsystems transforms, it is possible to divide out the system transform, in particular, the transducer frequency response. However, If the transducer has an inappropriate beam pattern and frequency response it may result in a very bad signal-to-noise ratio at the place 
in the spectrum which most strongly affects the accuracy of the results. Little frequency content in important regions could result in inaccurate signal processing. As one of the participants in the Ultrasonic Standards Workshop remarked: "Garbage in equals garbage out."

4.1.9. With the many advances in electronic technology, why are there problems in calibrating the electronic equipment?

There seem to be no scientific problems but rather some technological and practical problems in the calibration of the electronics. For example, it may be of interest to determine the peak voltage amplitude of the pulser in an ultrasonic unit. However, the Impedance of the transducer must be simulated in a specific way which is really a problem of specification, $1 . e$. what to measure and how to measure 1t. It should be noted that both NBS and ASTM Subcommittee E7.06 are dealing with such problems. It has been suggested that the electronic calibration or diagnosis problem could be solved by a builtin electronic test set resembling a radar test set or in using the NRL Electronic Test Block concept in some expanded way. This matter deserves further attention.

\subsubsection{What about standards for measurement of residual stress} and material properties?

There is a growing demand for standards for ultrasonic measurements of residual stress and material properties such as velocity and attenuation. Monitoring these characteristics is clearly important for the assessment of the life and performance of materials and components and therefore constitutes a valid extension of NDE from defect diagnosis to determination of material condition. When such measurements are made by researchers in their laboratory, the accuracy of the apparatus and measurement technique is assessed and improved in each individual case. However, when such measurements will be routinely performed in manufacturing and field environments, there will be a need for references and standards. The total requirements for standards for residual stress are still unclear because too little is known about the final techniques and their sensitivity to material condition. However, one can also imagine reference artifacts with different residual stress patterns. In the case of attenuation and velocity measurements one can imagine sets of reference materials with different velocity and attenutation characteristics for "calibrating" measurement apparatus. Significant interest has been noted in monitoring elastic modulus of raw stock by measuring velocity and specific requests for traceable velocity measurement and certification have been made. 


\subsection{RECOMMENDATIONS FOR RESEARCH AND DEVELOPMENT OF ULTRASONIC NDE}

STANDARDS

In this section we present recommendations for research and development of ultrasonic NDE standards based upon the source material and their analysis already observed in this report. The recommendations are organized into the following categories: 4.2.1. What needs to be done to improve existing standards or standards for existing systems; 4.2.2. To select for further evaluation proposed standards and calibration methods; and 4.2.3. To assess the requirements for standards and calibrations for developing ultrasonic systems. In section 4.2.1., we recognize that improvement of accepted standards, e.g. those proposed by ASTM, traceable to NBS, or those widely used in practice, will have an immediate and cost effective impact in improving the reliability and more quantitative use of current methods. It is also clear that improvements in these standards, in the underlying theory and in their relation to practice will have significant, direct impact on future systems. Section 4.2.2. deals with methods which have been proposed which are new, rather than improvements of those considered in section 4.2.1. The emphasis here is not in unexplored ideas but rather on the examination and possible implementation of the concepts for specific standards needs. Section 4.2.3. deals with standard and calibration needs for evolving and future NDE methods.

In considering the standards needs for ultrasonic measurement systems, the specific system and application must often be considered. However, as far as possible we have endeavored to make these recommendations broadly applicable.

\subsubsection{Improvements in standards for existing systems}

The emphasis in this section is on standards-related work that will impact conventional pulse-echo systems. The area is further divided into problems with transducers, reference blocks, and electronics. It should be recognized that solutions to standards problems of current systems wfill often carry over to developing or future systems, particularly those using pulse-echo techniques. For example, an understanding of the characteristics of the field produced by a transducer is important for conventional pulse-echo techniques; however, such detailed knowledge is vital for many developing techniques. In spite of dramatic developments that are forecast for quantitative NDE, it is expected that the majority of systems that will find use in the near future will still be pulse-echo based systems since many applications simply will not support the more advanced techniques.

\section{Transducer characterization.}

The transducer in an ultrasonic measurement system has probably the single greatest influence on the data obtained in an evaluation. This is true not only in present systems but will be even more so in most of 
the systems contemplated. The need for complete transducer characterization has been expressed by a large number of the participants in, for example, the recent ARPA/AFML Reviews of Progress in Quantitative NDE and the Workshop on U1trasonic NDE Standards (see Appendix B). The fields produced by the transducers are complex and the variability in their characteristics is high. There is a clear need for a better understanding of the theoretical and actual characteristics of transducers.

1. Necessary and Sufficient Transducer Specifications for Reproducible Results. The minimum specifications for a transducer to obtain reproducible results in flaw evaluation, even with the same instrument, are not known. Some experiments have been performed recently [27] using six transducers, all of which meet the specifications of ASTM E-127. Using the same instrument and normalizing the output for each transducer, differences in amplitude of response from the different transducers on the same reference blocks were found to average about $25 \%$. The implications for actual inspections are clear.

In developing these criteria it will be useful to determine whether any procedures (e.g. the very detalled British System, see [12]) are sufficient to specify transducers. After establishing appropriate criteria it may be necessary to develop the required measurement methods.

2. Theoretical Models for Transducers. Much of the standards work in and out of consensus organizations has been hampered by the lack of an appropriate theoretical model for the field produced by ultrasonic transducers. The usual model, that of a plane piston under continuouswave excitation into water, is clearly not appropriate and leads to a great deal of wasted effort trying to match or explain differences from "the" (imperfect) theoretical model. This and the item above should lead to improved transducer design and manufacturing uniformity.

3. Effects of Pulsed Excitation. The response of a system depends on the characteristics of the exciting pulse. This interaction is not well understood and leads to differences in measured response in spite of normalization on the same reflector. This problem deserves further investigation.

4. Longitudinal Transducers Characterization. Some useful methods for measuring certain characteristics of transducers have been or are being developed. These include radiation pressure for absolute power versus frequency, calorimetry for time-averaged power, and planar scanning for field quantities. However, since these are all laboratory methods, techniques for use in the "field" or user laboratory for determining at least the most important transducer characteristics should be developed.

5. Methods for determining the important characteristics of a transducer with a solid load should also be developed. The European 
practice of using a block and an EMAT recelver (which is not very sensitive to coupling varlables and doesn't load the surface) should be investigated in this connection. Non-contact optical methods may also be useful. In either case a deconvolution of the surface measurement is needed to determine the field in the solid. (Methods for the characterization of angle beam transducers should also be investigated and developed.)

Reference blocks.

At present ultrasonic NDE is a comparative measurement which relies on reference blocks for checking and adjusting the equipment, for forming a basis of agreement (contract between supplier and purchaser) and for establishing reject criterla. Although such measurements may be quantitative, they are really a measure of "relative reflectivity" of a defect at a given angle and this often doesn't indicate defect size. The reference blocks are and will continue to be an important part of the ultrasonic measurement system. Even in future systems, these or similar blocks will be used for comparing performance, demonstrating resolution, sensitivity, etc.

1. Transfer of Calibration. Even when the material for a reference block and a part under Inspection are the same alloy, different acoustic properties can cause great difficulty in using the block as a reference for making measurements in the part. For some steel and titanium alloys this problem overshadows any uncertainty in reproducibility of the reference blocks. A method for properly comparing the test and reference data should be developed. It would likely involve the development of field methods for the measurement of properties such as attenuation, velocity, and impedance. This problem area also has Implications for Item 3 below, "Quartz blocks."

2. Generic Reference Block Problems. There are certain problems which are common to nearly all specifications of reference blocks and product standards, for example, the specifications of surface texture. Although the present practice specifies only rms finish, evidence indicates that the return signal can differ greatly from blocks with the same rms surface finish. At least two parameters are necessary to specify texture but the relation to manufacturing methods are unclear. A need for appropriate models for the relation of the amplitude of the signal from a reflector as a function of metal travel distance is another problem that is common to reference and product standards and, in fact, to Inspection procedures. Some initial work at NBS based on fits of. models to a large data base of reference blocks [36] suggests that such a model could reduce the number of blocks needed for a distance amplitude set from about twenty to two or three. Additional work could result in greater economy, convenience and accuracy.

3. "Quartz" Blocks. The number of different sets of reference blocks required to do ultrasonic testing is formidable. Usually a different 
set of test blocks is required for each alloy, sometimes even each temper or texture. The development of a set of reference blocks "uncolored" by material properties, along with a compllation of transfer data for the material under inspection, would lead to a great economy for any standards effort. A transparent amorphous reference would eliminate metallurgical texture problems (the greatest single cause of block. variability). Also, for future systems, a need for references with negligible attenuation was indicated (see ARPA/AFML Review 1975). Such a conclusion was also expressed at Public Review of the NBS NDE Program in December 1974.

4. Relation of V, U, and EDM Notches to Cracks. Many product standards suggest the use of " $V$ ", " $U$ " or EDM notches as reference defects for the evaluation of products or cracks. The quantitative relation of these reference defects to each other and to actual defects is not sufficlently clear; see however reference [36a]. These relations should be established.

\section{Electronics}

1. Measurement Methods for UItrasonic Instrument Components. What are the right parameters to measure? How should they be measured? When different systems are operating properly (1inear, appropriate sensitivity, calibrated $d B$ control, etc.) and operating similarly in terms of resultant measurements there is limited interest in the characteristics of components; but, given a problem in performance, these characteristics become central. There are presently no accepted procedures describing what electrical quantities of the components of a system should be measured or how to measure them. See also 4.1.10.

2. Effects of Instrument on Transducer Performance. Several laboratories and suppliers have identified a problem associated with the interaction of the instrument and transducer characteristics. This is a more general problem than the problem of the effect of pulse characteristics mentioned previously. A symptom of the problem is the difference in center frequency as measured by a supplier (with his instrument) and as measured by the user (with the user's instrument). If instruments within certain categories have the same known electrical characteristics, it may be possible to develop methods to predict system performance so that tests can be run at the specified test frequency.

\subsubsection{Proposed standards and calibrations}

Many methods of standardization or calibration have been proposed in the recent past [13]. Some of these seem to offer many logical or practical advantages over currently accepted practices but are not widely used. Selected methods should be more completely analyzed (see sections 3.2.2., 3.2.3., and 3.3.3.) with logical standards criteria and promoted if they indeed prove to be significantly advantageous. The emphasis of the analysis should be on whether the basic concepts are 
sound and whether the technique can be made to work. This process takes more time and effort.than is generally recognized. Independent, statistically valid procedures and error analyses must follow even the best technical develppment in order to properly establish a proposed standard. In addition, it is frequently necessary to develop an interactive loop with the users.

1. Theoretically Described Scatterers. It is possible to theoretically describe the reflection, diffraction and scattering of certain geometrical reflectors of regular shape. When this is possible, what is the role of such a theoretical description in the development of standards and calibrations? Can theory be used as another parameter which characterizes a test block; can it serve as a means for transferring the calibration of an ultrasonic system from test block to test block and can it serve as the foundation of a primary, traceable standard block? Does it give any benefits for an overall systems check? Existing theories which describe the scattering of infinite plane ultrasonic waves and pulses from cylinders, spheres and other smooth obstacles such as ellipsoids should be extended to include the scattering of non-planar, bounded ultrasonic waves which most closely resemble an actual ultrasonic testing and calibration situation. Theoretically described blocks must also be developed and examined in the context of a criteria such as given in 3.2.2. and 3.2.3.

2. Transducer Field Characterization by Planar Scanning. An elegant theory has been developed for the very economical determination of the complete ultrasonic field quantities produced by transducers [37]. At least two methods of obtaining the required information have been conceived: one using a receiving hydrophone and one using laser scanning of a pellicle [14]. If the analysis for deconvolving the free surface of a solid were developed, the method could be used for determining the field quantities in a solid. Also, the method has the potential for examining pulsed fields. This proposed method - planar scanning - requires additional work before it becomes an established method. Other sound field visualization techniques such as photoelastic methods should also be investigated.

Planar scanning is recognized as an advanced laboratory method. However, it can be done quickly and with great economy and can provide just the level of information detail required. In any case it is envisioned that at least every line of manufacturers' transducers and new design approaches should be analyzed for rather detailed field patterns as a way of meeting manufacturing design criteria.

3. Well Characterized Fatigue Cracks. The goal of most in-service inspection is the detection and evaluation of fatigue cracks. In order to evaluate new measurement systems (and new procedures with conventional techniques) it has been proposed that fatigue crack specimens with known characteristics be developed. Some parameters can be controlled in specimen production; others must be evaluated in terms 
of ultrasonic response. Careful design of the loading program can minimize effects of crack topology and crack closure [19]. However, the details of the functional relationship of stress intensity at the crack and of relative geometry of the crack and transducer on ultrasonic response must be determined.

4. Electronic Test Block (ETB). The use of an electronic test block at least to partially replace reference blocks has been proposed for several years [38]. The ETB, which electronically generates and controls signals which simulate the return signals from reference defects, offers some clear advantages over presently accepted systems. However, questions remain such as loading of the transducer, stability and relation to material under test. Possibly, a more natural and spectallzed use of this concept may be in determining and monitoring the electronic performance of the instrument. One could envision this as being analogous to the radar test set, possibly even incorporated into the flaw detection instrument.

5. Other Proposed Methods. Other methods for Improving the standards system have been proposed. Some interesting work on blocks simulating even inclusions has been initiated [39] (see also appendix B): These should be critically screened so that the most promising could be further investigated.

\subsubsection{Standards for developing methods; quantitative NDE.}

Advanced ultrasonic NDE systems are being developed to make quantitative measurements of flaw geometry, orlentation and size, rather than "relative reflectivity" and to decrease the dependence on operator interpretation. However, one must not expect that these developments w111 automatically decrease the need for standards. Standards w111 not only st1ll be needed but may be even more complex because the amount of signal extraction, comparison and processing will be even greater. No matter how quantitative the system, in the end one must validate its condition and performance. Although functional checks of the overall system performance may not be more complex, the diagnostic checks necessarily will be.

It also seems clear that the advent of computer-based systems will reduce operator dependence in both calibration and the actual NDE measurements, but still not eliminate the need for standards.

1. Imaging Systems. It has been speculated that standards will not be needed with imaging systems since a picture of the flaw is presented. A comparison between $x$-ray lmaging (where standards are required) and ultrasonic imaging indicates a greater need in the latter because the use of longer wavelengths in relation to object size degrades image quality. At least resolution, focus, and grey scale definition must be established and monttored. As with any reference standard these should permit relative performance measurement and data interchangeability. A 
possible standard could have artificial defects of various sizes with various three dimensional spacings and at various orientations. The defects could be constructed to have various impedances. A scheme similar to the one used by the American Institute of Ultrasound in Medicine for their blocks could be used to simulate materials with different attenuations [40]. Some of the newer fabrication techniques such as diffusion bonding or powdered metallurgy (and including, e.g., silica inclusions) may be used to implement these standards. It would be appropriate to develop such prototype blocks and investigate their efficacy using state-of-the-art imaging systems in response to this developing need.

2. Adaptive Systems. Adaptive systems presently make use of many different variables and combinations and powers of variables in the correlation of response with defect characteristics. Since this would seem to make the technique particularly sensitive to the data used in the learning process, it would seem necessary to provide input using a large variety of characterized defects. Well-characterized fatigue cracks as described in Section 4.2 .2 and [19] may provide a valuable teaching aid if implemented. It also may be useful to employ the arsenal of actual reference defects which were used to develop the ASTM reference radiographs. Theoretically described defects would also be very valuable in system training.

3. Fourier Transform Methods. Present ultrasonic methods often employ only two parameters: time of arrival and amplitude of reflected signal. At most, therefore, two features of a defect can be determined from a single measurement, depth of the defect and its relative reflectivity. Fourier transform methods attempt to use a continuum of frequencies associated with the return signal in order to determine more features of a defect. Transform techniques may be either of the pulse echo or scattering varieties. In the latter case, the use of theoretically described scatters would be helpful. Workers in this activity point to a much greater need for knowing the details of the transmitted signal and for a great need for control of more characteristics of reference defects used with these techniques.

4. Standards for Material Measurements. There is great interest in measuring quantities such as residual stress, grain size, hardness, attenuation and velocity by ultrasonic techniques. Reference artifacts or procedural standards will certainly play an important part in the establishment or improvement of these measurements. For example, the measurement of residual stress relies on establishing a point of reference, e.g., a zero stress state. Methods and standards to do this are needed if the techniques are to be used for the measurement of more than a change in stress state due to applied load. 
4.3.1. There are a great many problems but what are the priorities?

An integrated approach to the issue of improved ultrasonic standards requires addressing the three areas in which work is required:

a. Improve current standards where the emphasis is on the pulse echo technique,

b. analyze proposed standards for possible implementation,

c. develop standards for emerging techniques.

While it is convenient for discussion to compartmentalize these activities, there is much overlap in these areas. Thus, work on proposed standards (item b) should result in implementing improvements in current standards (item a). Similarly, some proposed standards (item b) really address forseeable problems in emerging techniques (item c).

We suggest that 1 it is necessary to support and improve current standards because they will be in use for some time and because it is cost effective to do so. We do not belleve that emerging technology, e.g. smart and imaging systems, will cause the more primitive pulse-echo techniques and the standards on which they rely to become obsolete. The. newer techniques will be more complex, costly, difficult to maintain and will require more complex standardization. Furthermore, there will continue to be a need for the qualitative tests the present systems can fulfill. It also seems clear that the standards and calibrations being developed will be useful for the more complex evolving systems either as they are or by sote adaptation. Thus, it appears that for current needs and future applications, improving current standards is necessary and valuable. Although it is difficult to suggest precise allocations for the major areas, national needs seem to strongly suggest a balance be maintained among the major areas of effort.

We now attempt to address a more specific question of priority regarding relative emphasis for developments in reference blocks, transducer characterization and measurement of electronic characteristics. Ultrasonic systems generally are composed of an electronic apparatus and display, a transducer and frequently some apparatus for determining system performance such as reference blocks. While some effort on improved reference blocks seems certainly justifled, recent work on reference blocks indicates they can be successfully fabricated if due attention [11] is paid to material selection and fabrication techniques. When coupled with an available calibration service, the problem of variability is solved for one type of block made of aluminum. While the development of improved blocks and a more general calibration service is desirable, we caution again that it may not be reasonable to expect some new "super" block. However, growing concern has been expressed for a more direct and descriptive characterization of transducers than can be obtained from reference 
blocks. In addition, the need for separate electronic calibration has received increasing attention. The priorities would seem to be first transducers, second - electronics, and third - reference blocks.

\subsubsection{If a11 the problems are solved, what impact can be expected?}

If the problems discussed in Section 4.2 are solved, current NDE will certainly be made more reliable and quantitative, and in addition the basis for standards for emerging quantitative systems will be established. The importance of NDE in conjunction with fracture mechanics in assuring the integrity of existing and future high performance structures is obvious and relies heavily on a reliable quantitative measurement system. As has been shown, the realization of this goal relies very directly on improved standards and calibrations as well as on new techniques. By anticipating the standards needs of the future, particularly of intrinsically more quantitative methods, the time until field application is made will be decreased and the operational utility of the method will be enhanced.

Although the list of problems in Section 4.2 is meant to be rather comprehensive, it should not be regarded as a fixed work plan. As some of the high priority problems are solved, a reevaluation of the measurement needs may indicate that not all of the other problems need be solved. On the other hand, it is apparent that unforseen problems may also arise.

It is difficult to estimate the fiscal benefits of the solution of the standards problems to ultrasonic NDE measurements. However, a recent study on the "Economic Impact of Acoustic Measurement Uncertainty" attempts to deal with the fiscal benefits of standards work on ultrasonic NDE [41]. This report estimates that the cost of uncertainty for NDE in its many applications might be of the order of \$150-300 million per year. The larger question of measuring the wrong quantity independent of uncertainty is one of even larger economic impact, probably by orders of magnitude. Other aspects of the reliability of ultrasonic measurements such as product liability also have significant economic impact and a heavy reliance on standards. In summary, analysis of the problem indicates that better standards and procedures have high significant economic benefits regardless of whether the standards are for current, rather qualitative methods or the emerging, more quantitative methods.

\subsubsection{Final comments}

As stated in the Introduction, the objectives of this study include:

o examine the present system of standards,

o assess the standards needs for emerging systems, 
- recommend a course of action to improve, supplement or replace the current standards system for ultrasonic NDE.

We have tried to realize these objectives within the constraints of a very complex measurement system that is very dependent on the wide diversity of techniques and applications. Although some of the results could have been foreseen, a number of others may be surprising. The conclusion may be disappointing that while there may be room for a greatly Improved block there is no universal new "super" block on the horizon. In addition, the strong evidence that new advanced systems will place even greater demands on standards may also be surprising.

In addition to this report, this work has a number of other outputs which are published separately. These include the discussion of US and European Standards [12], an extensive survey on ultrasonic transducers and their characterization [14] and a bibliography of the literature relevant to ultrasonic standards [13]. It is hoped that this report and the associated documents w111 serve as a resource document in the area of standardization of ultrasonic NDE measurements.

Finally, the Workshop on Ultrasonic NDE Standards, summarized in Appendix A proved to be very valuable in developing this report and should be useful in future studies. 
[1] Panian, F. C. and Van Valkenburg, H. E., Development of ASTM Standard Reference Blocks for Ultrasonic Inspection, Proc. of ASTM Vo1. 59, 1959.

[2] Commission V, Use of Reference Blocks for Checking Ultrasonic Inspection Apparatus, British Welding Journal, April 1960.

[3] Rawlings, H., Ultrasonic Testing Standards, Ultrasonics, Jan.March 1963.

[4] Tentative Recommended Practice for Fabricating and Checking Aluminum Alloy Ultrasonic Standard Reference Blocks, E127-58T, 1958 Book of ASTM Standards, Part 3.

[5] Burley, C. E., Calibration Blocks for Ultrasonic Testing, in Nondestructive Testing - A Review, H. Berger, editor, ASTM STP 624, p. 146, 1977.

[6] Eitzen, D. G., Sushinsky, G. F., Chwirut, D. J., Bechtoldt, C. J., and Ruff, A. W., Improved Ultrasonic Standard Reference Blocks, NBSIR 75-685, April 1975.

[7] Standard Recommended Practice for Fabricating and Checking Aluminum Alloy Ultrasonic Standard Reference Blocks, E127-75, 1976 Book of ASTlY Standards, Part 11.

[8] Standard Recommended Practice for Fabrication and Control of Steel Reference Blocks Used in Ultrasonic Inspection, E428-71, 1976 Annual Book of ASTM Standards, Part 11.

[9] Millman, I., An Improved Facility for the Calibration of Aluminum Alloy Ultrasonic Reference Blocks, Report No. AQD/NDT 1369, AQD Labs, Harefield Uxbridge, Middlesex, U.K.

[10] Weston, H. W., Harrogate Symposium on Standards in NDT, organized by the British National Committee for NDT, Sept. 1962.

[11] Chwirut, D. J., Recent Improvements to the ASTM-Type U1trasonic Reference Block System, NBSIR 79-1742, April 1979.

[12] Golan, S., A Comparison of American and European U1trasonic Testing Standards, NBSIR 79-1790.

[13] Eitzen, D. G., and Birnbaum, G., Summary of the Literature on U1trasonic NDE Standards, NBSIR in preparation. 
[14] Sachse, W., and Hsu, N., Ultrasonic Transducers for Materials Testing and Their Characterization, Physical Acoustics Vol. 14, 1978.

[14a] Belanger, B., Traceability - An Evolving Concept, to be published in ASTM's Standardization News.

[14b] Compilation of ASTM Standard Definitions, p. 600, Third Edition, 1976.

[15] Chwirut, D. J., Sushinsky, G. F., and E1tzen, D. G., Procedures for the Calibration of ASTM E 127-Type Ultrasonic Reference Blocks, NBS TN 924, September 1976.

[16] Adler, L. and Lewis, D. K., Diffraction Model for Ultrasonic Frequency Analysis and Flow Characterization, Materials Evaluation, January 1977.

[17] Sachse, W., Hsu, N., and Eitzen, D., Visualization of TransducerProduced Sound Fields in Solids, 1978 Ultrasonic Symposium Proceedings, IEEE Cat. No. 78CH1344-1SU.

[18] Fick, S. E., An Optical Doppler Probe for Ultrasonic Waves in Solids, Proceedings of the 1978 Conference on Information Sciences and Systems, March 29-31, 1978, Johns Hopkins University.

[19] Chwirut, D. and Eitzen, D., Toward the Development of Improved Reference Fatigue Cracks for Use in Ultrasonic NDE, to appear in Int1. Adv. in NDT.

[19a] Tittman, B. R., Thompson, D. O., and Thompson, R. B., St andards for Quantitative Nondestructive Examination, in NDT Standards: A Review, H. Berger, Editor ASTM STP 624, p. 295, 1977.

[19b] Tittman, B. R., and Thompson, D. 0., Approach to a Self Consistent Calibration Procedure of an Ultrasonic. System, Materials Evaluation Research Supplement, April 1977.

[19c] Tittmann, B. R., New Procedure for Calibrating Ultrasonic Systems for Quantitative NDE. Proceedings of the ARPA/AFML Review of Progress in Quantitative NDE. AFML-TR-77-44, 1977.

[20] Kino, G., Khuri-Yakub, B., Murakani, Y., and Yu, K-H., Bulk Defect Characterization in Ceramics, 1978 ARPA/AFML Review of Quantitative NDE.

[21] Cohen, E. R., Analysis of Ultrasonic Wave Scattering for the Characterization of Defects in Solids, final report to AFOSR; May 1977, Rockwell International Science Center, Report No. SC579.4: 
[22] Gubernatis, J. E., Domany, E., Krumhans1, J. A., and Huberman, H., The Born Approximation in the Theory of Elastic Wave

Scattering by Flaws, J.: Appl. Phys. 48, 2812 (1977).

[23] Pao, Y. H., The Transition Matrix for the Scattering of Acoustic Waves and for Elastic Waves, Modern Problems in Elastic Wave Propagation, Wiley-Interscience, New York, 1978.

[24] 1978 ARPA/AFML Review of Quantitative NDE.

[25] Liddington, B. H., and Silk, M. G., The Variability of Ultrasonic Transducers, British Journal of NDT, November 1972.

[26] Chwirut, D. J. and Eitzen, D. G., Improving the Reliability of Ultrasonic Measurements: Recent NBS Progress, ASNT Proceedings 1978 Spring Conference.

[27] Chwirut, D. J. and Boswe11, G. D., The Evaluation of Search Units Used for Ultrasonic Reference Block Calibrations, NBSIR 78-1454, February 1978.

[28] Miller, E. B. and Eitzen, D. G., U1trasonic Transducer Characterization at the NBS, IEEE Transactions on Sonics and U1trasonics, Vo1. SU-26, No. 1, January 1979.

[29] Smith, V. D., Teller, C. M., and Swanson, R. K., Engineering Services to Determine Acceptance Limits of U1trasonic Transducers for Nondestructive Inspection, SWRI Project No. 15-5024, June 1978.

[30] Chwirut, D. J., A Simple Technique for Visualizing Transmitted or Reflected Sound Fields, to be published in a Materials Evaluation as a Tech. Note.

[31] Hildebrand, B. P. and Collins, H. D., Evaluation of Acoustical Holography for the Inspection of Pressure Vessel Sections, Materials Research and Standards, Vo1. 12, No. 12, pp 23-32 (December 1972).

[32] Metals Handbook, Vo1. 11, 8th Ed., ASM, p. 231 (1976).

[33] Mucciardi, A. N., Measurement of Subsurface Fatigue Crack Size Using Nonlinear Adaptive Learning; Proceedings of the ARPA/AFML Review of Progress in Quantitative NDE, Pp. 194-199, AFML-TR-7744, September 1977.

[34] Yee, B. G. W., Kuselman, J. S., Walker, T. C., Gardner, A. H., and Robinson, A. R., Computer-Automated Ultrasonic Inspection Systems for Aircraft Forgings, AFML-TR-75-82 (May 1975). 
[35] Sonoray-Vessel-Scanner, Automatic Weld Testing System, Catalog Rontgen Technische Drenst, 144 Delftweg, 3046 N Rotterdam, Holland.

[36] Chwirut, D. J., NBS, unpublished results.

[36a] Birchak, J. and Gardner, C., Comparative Ultrasonic Response of Machined Slots and Fatigue Cracks in 7075 Aluminum, Materials Evaluation, December 1976.

[37] Kerns, D. M., Scattering-Matrix Description and Nearfield Measurements of Electroacoustic Transducers, J. Acoust. Soc. Am. Vol. 57, No. 2, Feb. 1975.

[38] Chaskelis, H. H., A Materials and Defect Simulator for Calibrating Ultrasonic Equipment Used in NDT, NRL Report 6984, Naval Research Lab., Dec. 1969.

[39] Conn, D. L., New and Improved ASTM Type Ultrasonic Standard Reference Blocks. Presented at International Symposium on Ultrasonic Material Characterization, NBS, June 7, 1978, to be published.

[40] Smith, S., Lopez, H. and Stewart, H., Methods and Results of Dynamic Range Testing of Diagnostic Ultrasound Instrumentation, Proc. of the Soc. of Photooptical Instrumentation Engineers, Vol. 127, Sept. 1977 .

[41] Kane, K. M. and Eldred, J. A., Bolt Beranek and Newman Report No. 3538 .

[42] Sachse, W. H., Golan, S., in Elastic Waves and NDT of Materials, ASME AMD, Vol. 29, Edited by Y. Pao, p. 17, Fig. 5, 1978. 

Workshop On Ultrasonic NDE Standards (October 17-18, 1977, NBS, Gaithersburg, MD)

We present here a detailed summary of the proceedings of the Workshop on Ultrasonic NDE Standards, trying to preserve as much as practical some of the flavor of the free exchange of ideas, criticisms, comments and suggestions. That there will be numerous contradictory statements or statements that invite strong disagreement is inevitable in an area which is intrinsically very complex and where there are numerous unresolved problems. These, too, have been retained. No attempt is made here to assess the results of this workshop, although a summary presented at the time of the workshop, but before the general discussion sessions, is included. Many of the important issues discussed at this workshop are highlighted in section 4.1 Key Issues.

The program of this workshop and list of attendees are presented as part of this appendix. Instead of following the structure indicated in the program, it proved more useful to organize the material in the following way:

1. Test Blocks

2. Transducers

3. Electronic Instrumentation

4. Operator Problem

5. Material Characteristics

6. Standards Implications for Developing Systems

7. Quantitative NDE

8. Directions, Problems, and Approaches

9. ASTM Ultrasonic Standards

10. Role of NBS

11. Summary 
WHAT FOLLOWS IS A DETAILED SUMMARY BASED ON THE TRANSCRIPTS OF THE WORKSHOP. THE SUMMARY IS MADE UP OF PARAPHASING TO CLARIFY, SHORTEN OR IMPROVE THE PRESENTATION AND DIRECT QUOTATIONS. IN NO CASE IN THE PREPARATION OF THIS SUMMARY DID THE AUTHORS INTERJECT THEIR VIEWS.

\section{Test Blocks}

The following definitions, distinguishing among the various uses of blocks, were put forward. A test block is a plece of material with a known defect and resembles as closely as possible the part under study. A calibration block has known dimensional characteristics or size of discontinuity and is at least reproducible mechanically. A reference block 1mplies that it has a use as a standardization tool. A standard reference block Imples that the response from the block can be referenced back to some known target by a prescribed accepted procedure. The definitions have not been documented.

The need to clarify the above definitions and particularly the difference between calibration and reference standards and set-up standards was mentioned.

It was suggested that the large variety of blocks that are in use and have been proposed be classifled according to the material of the block, the type of reflector, and the outer geometry which provides the angular relation and distance between the reflector and the search unit.

There was much discussion on the widely used flat bottom hole blocks and their variability. However, 1t was shown at NBS that metallurgy is responsible for most of aluminum block varfability.

The thought was expressed that the effect of material aging on the performance of the blocks would quite likely be ten times less than the changes in a given measurement system.

Questions were raised regarding blocks: are they adequate, what are the problems with them, is NBS wasting its time offering a calibration service for them? One view is that the use of blocks are bound in specifications, and consequently, the blocks define the desired performance for inspection. They are also used to assess the quality of material. They may be inadequate, but they need to be maintained unt1l something better comes along.

However, if a quantitative NDE system comes along, flat bottom holes may not be the answer for standards since they do not deal with the problem of orlentation and their scattering cannot be calculated because they have sharp edges. Disagreement was expressed on the latter point. 
An 1mproved flat bottom hole block was described which is fabricated by starting with a conventional cylinder and cutting a wafer out of the block. A hole is drilled in this wafer and the block is reassembled and diffusion bonded in an inert atmosphere so that the surfaces of the. wafer do not oxidize. A pressure of 2000 ps 1 at $2000^{\circ} \mathrm{F}$ is applied for about 10 to 15 minutes to produce a cylindrical void in the center of a steel block. Because the wafer need not be centered, one block can be used for 2 distances. Wafer thickness can be varied. The vold could be sputtered with various substrates, for example, silica to simulate a silica inclusion matrix. This block is superfor to the conventional flat bottom hole because it is absolutely flat bottomed in contrast to a drilled hole. Ultrasonic tests show that the bond boundaries are Invisible.

Targets other than flat bottom holes (spheres, for example) have been considered, but they become astronomical in size for the frequencles, search unit diameters, and distances to produce the sensitivities that are needed for many inspection appilcations.

On the other hand, the infinite plate (an exactly calculable reflector) that was suggested for standardizing measurements produces very large signals that overload the front end of present day instrumentation when used with present transducers. Angulation is very critical, moreover, making it very difficult to peak the system on a flat plate.

The point was made that reference blocks frequently do not simulate real defects.

The standard reference block for examining a pressure vessel for a bolling water reactor according to ASME is a very massive test block which weighs several hundred pounds, hardly a portable unit and consequently a disadvantage.

The need for correction factors for curved surfaces was made clear in a report (due to Serabian) which showed that if flat blocks were used for calibration for tests on curved surfaces without a correction, errors as large as $42 \mathrm{~dB}$ may be encountered.

The problem with reference standards for ceramics arises from the fact that fracture toughness calculations have shown that flaws of the order of 10 to 100 microns may be critical. The problem of building standard reference blocks with flaws of that size is enormous. However, a block with inclusions of six different materials and ranging in size from .060 to .0001 inch serves as a kind of standard for NASA. In most tests, however, NASA is not concerned with rejecting materials as much as with ranking the materials because they are later going to be tested and broken. 
The need for standards in the testing of composites was highlighted.

A great deal of work needs to be done to produce artificial flaws, (i.e. reference fatigue cracks) that are more accurately representative of the type of void that is being encountered in materials or structures in service.

A common standard or reference for set-up to detect fatigue cracks includes a triangular slot in an object simulating the structure under scrutiny. The operator proceeds to interrogate the actual structure after assuring himself that the equipment has responded properly to the simulated flaw in the standard.

A problem lies with the fact that we do not know what is transmitted so that what comes back doesn't tell us too much. Therefore, we use reference blocks. Many years ago, it was felt that there were too many reference blocks for this purpose, and this led to the idea of an electronic test block (ETB). It receives the acoustic pulse and later generates another acoustic pulse which is proportional to what is received. The proportionality is adjustable. The electronic test block has not been successful because we do not know enough about the transmitted beam. With any reference block, we must have some a priori knowledge about the beam. A more successful use of the ETB is as an instrument evaluation tool because there is control of time and amplitude which allows one to check for resolution and instrumental linearity.

\section{Transducers}

Many participants suggested that the transducer is the most critical element in the calibration procedure.

One needs to know the characteristics of the acoustic beam if one is to avoid variances in testing blocks. Once the acoustic beam is characterized for its pressure:amplitude and spatial location, one can use some universal test block such as the ETB where amplitude and time is controlled.

Evidence was presented to show that the response function of the search unit is different when driven $C W$ than when pulsed. Although under CW excitation the search unit may act as a piston, it may not do so under pulsed excitation. Nevertheless, using a microprobe, no difference was observed between $\mathrm{CW}$ and burst $\mathrm{CW}$ down to perhaps 9 cycles.

Other transducer problems were noted. When a typical $5 \mathrm{MHz}$ quartz crystal unit is pulsed, its frequency shifts. Although it was claimed that a great deal of experimental work agrees "reasonably" well with theory if we assume a piston motion for transmission, there is evidence 
that the transducer does not act as a piston on reception since adjacent sections of the crystal vibrate essentially independently of each other. It appears that the search unit that is going to be used for the calibration of blocks should be theoretically defined and designed. For

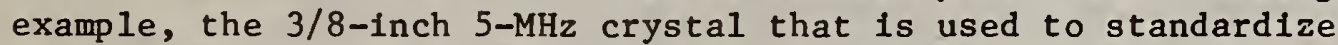
reference blocks gives results not in conformity with theory. Is it proper to use such a procedure? There appears to be some question regarding transducer linearity and stability especially in ceramic transducers. There is a problem in obtaining the desired center frequency of a transducer since the electrical pulse and loading at the manufacturing facility and that of the user are not the same.

Everyone is aware of the variability of transducers. We need to know more precisely the fundamental frequency, bandwidth, energy level and beam profile. The question of how components interact is important. For example, it is recognized that the type of pulse created by the pulser can affect the way the transducer reacts. Also, the pulser puts out a different type signal when it is in the unloaded condition. Different transducers may make the pulser react differently. This, then, raises the question of what are the conditions under which components should be evaluated to make the results meaningful.

There is a need for characterizing transducer variables such as beam spread, damping characteristics and frequency for peak response. These quantities are not well-defined in ultrasonic NDE practice in the nuclear industry which is based on the ASME Boller and Pressure Vessel Code. Furthermore, there is no provision for keeping track of them from one examination to the next; e.g., large temperature varlations can have an effect on transducer characteristics.

If one knows the electronic components, which are easier to quantify than characterizing the transducer, then one could know if the transducer is degrading the performance of the system.

A suggestion was made for transducer calibration using an ideal transducer, one whose characteristics are known and is broadband for use as a standard sound source and recelver.

Transducers should be calibrated in conjunction with the medium with which they will be used since there is a serious question whether the sound profile in a solid is the same as in water, the medium used for many calibrations.

The use of EMATS whose design and performance may be described by theory was suggested for the calibration of other types of transducers such as the piezoelectric type. Since the frequency characteristics of EMATS are also well-behaved and predictable, one may be able to use them to test the electronic system. 
Regarding the NBS role in the development of suitable transducers, it was said that NBS is not going to market transducers or compete with industry in providing transducers. NBS is, however, deeply concerned about different transducers giving the same results and examining various methods for measuring transducer properties. NBS has considered building transducers that may be regarded as standards in the sense of a standard reference material for various applications such as to check the results of spectral analysis, measurement of the power spectrum, etc. Although NBS is not in the manufacturing business, it was suggested that it should somehow get some good design information to the manufacturers. The question regarding the NBS role was again: does industry wish NBS to offer reference transducers or calibration services? Are there other properties of interest besides total power, frequency response, beam profile and electrical characteristics? It was noted that although NBS work on transducers thus far has concentrated on CW use, plans are under way to attack the pulse problem.

If "suitable" standard transducers were avallable, an imaging system's performance could be determined without the complicated problem of transducer characterization. Emphasis on absolute performance standards (e.g. resolving reference defects) rather than on procedural standards would then be possible at a great savings.

It was also suggested that NBS develop simpler field laboratory techniques for transducer evaluation.

\section{Electronic Instrumentation}

The point was stressed that it is very important to know the frequency and bandwidth of various parts of the system such as the transducer, pulser and amplifier. If one, in addition, considers that the ultrasonic responses from flaws have a variety of frequency dependencies, the net result of all these parts of the system, if misaligned or not compatible, can have strange effects on the output signals. The pulser, in particular, is a very important part of the system which affects the search unit and is affected by it. It is necessary to look at the specifications of the electronics and search unit and ascertain whether instrumental adjustments are consistent with these specifications. Despite this presentation, someone commented later that if you could set-up on the standard provided and if there is any reasonable dynamic range, the problem is not primarily with the electronic equipment.

The need to bulld instrumentation with greater uniformity of performance was mentioned.

A number of people emphasized the importance of developing a standard procedure or recommended practice for evaluating ultrasonic systems and their components. These standards should enable the user as well as the manufacturer to evaluate the equipment performance by a 
common procedure. Many electronic characteristics of an ultrasonic system vary considerably from one system to another as well as with time. These characteristics include: voltage, rise time and width of the pulse, recelver bandwidth, linearity of amplifier response over useful frequency range, bandwidth of gating circuit, and proportionality of the signal passing through the gate to the recorder. The phase response also should be added to this 11st in some applications. A basic problem regarding the electronics is to know how the instrument perturbs the incoming signal. Is this signal actually proportional to the signal recelved by the transducer? How do the components when connected interact and influence each other? What are the conditions under which components should be evaluated to make the results meaningful?

The potential of what could be learned from experience with radar was mentioned. In particular, should we have an ultrasonics test set analogous to the radar test set, a neat little package for measuring the performance of the electronic instrumentation?

Another way of going about the calibration problem is in analogy with testing high fidelity equipment and is basically the method of using a test sound recording for overall system evaluation. The distinction was made between much specific technical qualifications of the various parts of the equipment versus a standard which tests the end use. However, if one takes the latter approach to the extreme, then problems of reproducibility arise. You may get the sound you want but if something breaks down, how do you replace it with a unit of similar characteristics? The problem then reduces to determining the minimum number of critical tests, purely electronic, which would satisfactorily describe the electronic performance. In any case, if we had a minimum number of tests which are accepted by industry, the vendor could list these specifications when he sells the equipment. If one knows what to ask for, the Air Force as a major buyer of equipment, for example, could require bids giving those specifications.

\section{The Operator Problem}

The seriousness of the operator problems was highlighted by the following study conducted by the Air Force Logistics Command. A common reference for set-up to detect fatigue cracks uses a triangular slot in an object simulating the structure under scrutiny. The operator proceeds to iterrograte the actual structure after assuring himself that the equipment has responded properly to the simulated flaw in the standard. The operator is conditioned to a "can" $t$ miss" frame of mind when he sets up the equipment on the standard. What he sees is usually a clean signal using a well specified set of conditions on a simulated flaw in a known location. Contrast those conditions with the actual flaw detection with ragged signals of varying structures confused by nolse which may or may not contain flaws in any of a number of possible locations. It is very easy to miss a flaw in the real world 
situation. Reliability of detection was emphasized in this study rather than precision in assessing flaw characteristic.

The Air Force Logistics Command has gained some insight to the difficulty of the problem through a field evaluation of its capabilities. This program takes structural hardware to the field and depot environment where technicians conduct NDI tests on this hardware with their own equipment in the conditions they normally work. Detailed procedures are supplied and each participant can ask any questions about the task and seek help in setting up the equipment and help in finding out how to perform the task, which is to detect fatigue cracks and report their locations. The procedure calls for ultrasonic shear wave NDI at $5 \mathrm{MHz}$ with a 70-degree transducer. A wide variability in results was obtained. The best performer detected 33 of 42 flaws in a section of wing box containing slightly over 500 inspection sites, while the three poorest performers detected none. The results of this study showed that the most significant influence on detection capability may be attributed to the operator himself. The base that found the most flaws has a good certification program and is selective in the selection of testing personnel.

The demands of calibration and the set-up of equipment which is automated will require the use of skilled operators. Yet the statement was made that we must get rid of the inspector.

\section{Material Characterization}

The need to know material parameters was emphasized a number of times during the course of the workshop. This may be of particular importance, for example, in working with dispersive materials such as graphite (nuclear industry) which strips off the high frequencies.

Anisotropy in welds creates significant problems for ultrasonic examination and problems for standardization. Scattering within the weld due to anisotropic variations or grain structure variations may mask a defect or create a false indication.

Standards are needed not only for performance tests of equipment, but also those related to material performance. The need to specify surface conditions, such as roughness and waviness, was stressed.

Raw materials vary significantly in properties, in particular, attenuation. There are data to show that errors up to $20 \mathrm{~dB}$ may occur even using the concept of transfer of attenuation to try to account for such material variations. Large temperature variations as encountered in the nuclear industry can have a large effect on the sound attenuation in materials. 
NASA has to deal with a wide range of materials, nickel-base alloys (superalloys), titanium alloys, aluminum-based alloys, and a wide range of composites, metal and non-metal matrix composites. Such a wide variety of materials makes the use of ultrasonic standards difficult. Nevertheless, NASA uses conventional flat bottom holes whenever it is necessary. to set up some sort of accept/.reject criteria.

Composite materials are very dispersive and tend to vary quite a bit with moisture content. These factors make the use of standard reference blocks difficult.

NASA has a program whose intent it is to develop the preliminary means of estimating fracture toughness using ultrasonic measurements such as attenuation and velocity. Such measurements are used to monitor the onset and extension of fatigue cracks and fracture toughness during tests.

There is a need to establish a program to make quantitative measurements on the acoustic properties of materials, particularly attenuation and scattering.

\section{Standards Implications for Developing Systems}

Imaging systems

The wavelengths, generally speaking, are the same order of magnitude as the defects we are trying to look at in imaging systems; therefore, there is a resolution problem. There is certainly an identification problem because things do not look the way we are accustomed to seeing them look. Consequently, what is needed for calibrating imaging systems is a set of reference images, something like the radiographers use. Size and resolution calibrations are required. Side drilled holes at various depths and different spacings have been used to test the resolution and quality (focus) of imaging systems. A set of balls whose spacing is varied has been used to demonstrate spatial resolution.

Although two years ago it was said that for imaging no standards are required (except perhaps for size calibration), a position taken again by some at this workshop, the present view is that ultrasonic imaging has a long way to go in sophistication before we get to that point. So meanwhile, we must still rely for calibration purposes on the flat bottom hole, side drilled hole or some other artifact.

\section{Scattering methods}

In order to utilize scattering information properly, a suitable calibration procedure has to be capable of using multifrequency information. It should be amenable to calibration of either a pulse echo or pitch-catch system. A key aspect to the solution of this 
problem is the use of theoretically characterized scattering objects, although one could use empirical characterization. However, when one or few standards are desired for many frequencies and experimental situations, the number of measurements may become prohibitive, whereas theory can be used to generate efficiently the required solutions.

Given a spherical scatterer in a solid, one can develop a selfconsistent calibration procedure in the following way. One can formulate a transfer function which in the frequency domain is just the product of the transfer functions of the individual components of the system. The purpose of the calibration procedure is to isolate and define separately the transducer, the medium, the scatterer, etc. so that the frequency dependence of the scattering object can be separated from the rest of the system. Thus, the absolute efficiency of the transducer is determined, the attenuation and diffraction losses of the material are measured and the electronic system is callbrated, the latter by purely electronic techniques. Now, to calibrate the complete system to determine whether it gives the correct answers, one determines whether the system gives the theoretically known scattering for the sphere. A sphere embedded in glass can be fabricated at low cost and provide a lightwelght standard which is portable and durable. It should have very low attentuation if properly made.

There were a number of comments regarding this approach. The problem of dealing with attenuation in the range equation was cited. Ideally, the attenuation should have a small effect on the signal compared with the target reflection. The effect of the difference of the loading of the transducer on glass and on the metal of the test object must be taken into account. Although a good test of the gonfometer device using the spherical scatterer would be to make pulse echo measurements from all sides to determine the variability of the response, this has not been done.

\section{Automation}

Computer-automated systems to automatically scan parts with complex geometry have been used in the aerospace industry. For testing such systems, a beveled block with flat bottom holes was used. Between scans of parts, the transducer is sent back to a certain set of position and rotation coordinates over the reference block. The computer makes sure a strong top surface reflection is recelved, and the back surface reflection is of reasonable amplitude. The transducer is then sent (by the computer) to another area of the block that has a flaw embedded in it and makes sure the time base is calibrated by checking the timing between the top surface reflection and that from the flaw. The transducers are checked by using the Fourler transform capability of the system. 
The use of advanced product standards, particularly for checking the performance of automated systems, was discussed. It was stressed that these have been very expensive to develop. Whether the flaw is natural or artificial, but particularly in the latter case, it is important to find out as much as possible about the flaw by a variety of methods if it is to serve as a standard.

For computer controlled systems where the computer is in total control, it will be particularly important to educate the computer. Since we have to know that the data that are being programmed are correct, a standardization procedure is a must.

Adaptive learning techniques

A difficulty with the adaptive learning technique is that it takes a great deal of data for training the computer. Where a defect is theoretically characterized, the network is easily trained on theoretical solutions and can be tested against experimental ones. As an example of this, the network may be trained with spherical scatterers and tested against ellipsoidal scatterers.

Some general remarks

If computer interpretation is to be reliable, the following must be accomplished: the means for measurement of pulser, search unft, energy transmitted, character of the defect as a function of what it does to the sound energy and the energy recelved by the search unit and amplified energy. In complex signal processing systems, it was stressed that the most important problem is to understand what one is doing so that the information derived from the processing is in reality meaningful. When using more and more features of a signal it may be necessary to control or standardize more and more features.

\section{Quantitative NDE}

A view was expressed that people have not asked the right questions in the area of standards. Given a better qualitative tool, improved standards will not make an incremental improvement in the overall capability in that the best that will come out is still qualitative. No matter how good standards are, a truly quantitative capability giving flaw size is not attainable using conventional pulse echo systems. Better standards alone do not make NDE more quantitative, although they make $1 t$ more reliable. Imaging systems to replace pulse echo systems of the same size, flexibility and cost are now feasible. Th1s w111 be a major step toward quantitative NDE because one can now see the defect and know its orientation. Assuming that quantitative NDE is going to have a major impact in the whole of $\mathrm{NDE}$, what does this mean regarding standards? The speaker said he did not know the answer and 
continued; this is what we are hoping the NBS/ARPA program 10 will resolve; hopefully, something gutsy that says what the role of ultrasonic standards would be in the future.

What then is the function of standards if we have a quantitative capability? The calibration of the instrument is one function. Should the standard be a collection of defects? Does it have to be absolute or relative? Costs, of course, must be a factor to consider. Should the standards be based on theoretical models? It would appear that they should provide a more solid foundation on which to base measurements. Finally, if after the approach is decided, what fabrication techniques are reproducible and affordable? There is a diffusion bonding technique that is very attractive in many ways. However, is there something cheaper which is satisfactory? In short, it is necessary to define the goals and that is what NBS should do. It is worth emphasizing that if we can really measure size, shape, and orientation, do we really need standards?

Current problems should disappear when NDE really becomes quantitative as $1 \mathrm{t}$ w11 in a few years. Such problems as are traceable to the operator will disappear when his current inferior tools are replaced with much better ones.

Granted that ultrasonics is moving heavily in the inaging area to obtain more quantitative results, the previous discussion was countered by the thought that standards w111 nevertheless be required regardless of how far ultrasonics or quantitative NDE advances. For example, it seems unlikely that quantitative NDE will advance beyond the stages of photography for quantitative results. Yet, we use standards to measure spatial resolution, the grey scale response, etc.

The universality of imaging system usage was challenged. For example, because of the inaccessibility of steam generating tubing, one must test this item in situ with pulse echo equipment. Although it is certainly helpful to know the size and character of a flaw with high precision, it first must be detected. The detection of flaws is a primary objective of NDI in the maintenance and production environment. However, with the advent of fracture mechanics, there is increasing need to know the exact size of a discontinuity.

The question was raised whether within the framework of quantitative NDE there is a basic difference between flaw detection versus resolution of the flaw itself. Is it a foregone conclusion that if you have a better method of resolving the flaw, you have a better method of detecting 1t? The answer to this question was that it depends on the sensitivity of the method. However, within the sensitivity range, if it is quantitative, there is a way of narrowing the curve for probability of detection.

10 Author's comment: the speaker is referring to the subject of this report. 
The opinion was expressed that a series of graded flaws would not be an approach to quantitative NDE. Trying to duplicate actual flaws has an infinite number of possibilities. Once we have a quantitative system, such as an imaging system, a test of its resolution will pretty well define the performance of the instrument. With such a test of resolution, standards will become well defined and rather clear. However, maintaining that performance or diagnosing a problem is another matter. But until that point is reached, we do not have quantitative NDE. Thus it may not be worthwhile emphasizing the systems that are presently in use, and consequently, standards for this system. Contrary to this thought, it was mentioned that it might take 20 years to make these systems reliable and by that time we will have something better, i.e. quantitative.

\section{Directions, Problems and Approaches}

There are two approaches to the problem of calibrating an ultrasonic NDE system: to measure the characteristics of all components of the system separately, or to calibrate the whole system at once using some appropriate block.

The issue was raised several times, which parameters of an ultrasonic system are crucial for the detection and characterization of flaws? Why should time be wasted in measuring 15 parameters if only 5 are, in fact, crucial?

Role of standards. Is the role of the ultrasonic standard to setup and to calibrate? Is it to be a basis for defect detection? Is it to be a basis for defect characterization or the basis for common comparison and communication? It was suggested NBS can offer a benchmark measurement to help a user calibrate a system.

The question of standards and codes in the German nuclear industry was discussed. In this country, we have committee (consensus) action which results in a code with minimal requirements. In Germany, there is a private company, under contract to the government which enforces the nuclear and other codes. The German codes are based on the DGS system of standards and calibrations, which was referred to favorably more than once in this workshop. The German requirements are based on a combination of theory and practice. For example, these requirements consider what happens if the search unit is not quite at the correct frequency. Also, a nomogram has been developed for obtaining the response of a flat bottom hole relative to that from a side drilled hole.

The Air Force indicated that it is committing over $1 / 2$ million dollars from 1978 through 1980 for the development of new standards, the technology for producing them and standards for manufacturers. A problem area of real concern for the Air Force is that although it 
look at the $95 \%$ confidence level, the probability of detecting flaws at that level is not very good in the field.

The Army noted that there seems to be an extension of the consumer protection act to the G.I. As a consequence, $100 \%$ inspection is required and automation is being heavily used. This means that built-in self-checks on the equipment are a must, also that actual standardized flaws would be helpful.

According to an account of the needs of the Nuclear Regulatory Commission, the problem of detecting and characterizing flaws arises from insufficient standardization and variation in ultrasonic equipment and procedures. For example, methods for measuring transducer characteristics such as beam spread, damping characteristics and frequencies for peak response are not well defined and there are no provisions for keeping track of them from one examination to another in the ASME code. Large temperature changes can have an effect on the transducer characteristics and on sound attenuation in the material. Similarly, pulser, receiver, amplifier, display screen size or linearity may vary from one inspection to another and influence the magnitude of the flaw indication. The needs are for well-defined ultrasonic procedures and standards. Present practice is based on the ASME Boiler and Pressure Code which has no standards for either ultrasonic systems or components.

Given the knowledge of all the characteristics of the transducer and all the properties of the electronic system, it may still not be possible to infer the actual performance of the NDE system. The biggest impact one could have in the short term would be to produce specifications for the electronics. The next thing would be to produce a standard which is not only reproducible, but would also work in calibrating an imaging system. On a lower level of priority, one should calibrate transducers simply and try to improve them. (Others thought this should be a very high priority.) It is not going to be worthwhile to do an extensive transducer calibration because it is complicated and expensive, and moreover too difficult to relate electrical-acoustical properties to actual performance. To this view should be contrasted the view that if a proper transducer calibration has not been accomplished, and if the transducer happens not to be stable, it will not be possible to know what has changed. It was also pointed out that the calibration of transducers may not be such a monumental task with improving methods, such as a simplified approach to obtaining field patterns. Again, the thought was expressed that such information cannot be related to actual performance. However, it was speculated that in an imaging system, the capability of the instrument could easily be specified.

\section{ASTM U1trasonic NDE Standards}

Although the current ASTM activity has been generated almost entirely empirically, it has much in common with the theoretically 
derived system which requires, among other things, the following: targets which are disk shaped, perpendicular to the axis of the sound beam, and have constant and essentlally 100-percent reflectlvity, disk diameters that are small compared to the beam diameter and usually larger than a half wavelength in the materlal, and target distances which correspond to the part thickness.

These conditions are essentially met for most of the commonly used search unit sizes, frequencies and test conditions by the test blocks provided in the ASTM distance-amplitude and area-amplitude test block set. Echo amplitude for constant target distance varles as the target area. For constant diameter, it varies essentially as the inverse square of the distance.

The disk-1ike targets in flat bottom hole blocks approximate typical flattened discontinuities actually found in forgings and raw stock such as plate materlal. The disk diameters produce echo amplitudes of the same order of magnitude. In other fields of inspection, for example, plpe and tubing and weldments, many other configurations of artificial defects have been used such as notches and side drilled holes. However, in general, these do not meet the original ASTM criteria established to provide a relatively neat physical target and to meet the sensitivity and amplitude requirement for test blocks.

Test blocks have the following advantages. They check a complete system: instrument, search untt, cable, connections and couplant for sensitivity and nolse level; allow a meaningful resolution check under actual operating conditions with a variety of search units and they establish initial set-up conditions. They can provide direct comparison of echo amplitude for determining material acceptabllity on a customerto-vendor basis. Test blocks have a number of disadvantages: they may be difficult to reproduce precisely; they do not easily allow a separation of search unit and instrument characteristics; it may be costly and time consuming to perform standardization and calibration using test blocks; even with the same block, reproduclbility may be difficult depending on operator capability; and, finally, there is a certain lack of versatility.

The ASTM aluminum blocks come closest to representing from the ASTM viewpoint a general purpose reference block. They meet the target size and distance requirements, and use a materlal that is more or less uniform. The blocks are made from a reasonably hard alloy so that they can withstand both contact and immersion use. They can be anodized against corrosion. If one wanted to test a steel part using these aluminum blocks and the attenuation was ruled to be negligible for short distances then only an impedance mismatch factor would have to be taken into account.

It was hoped that a large group of blocks could be made and held to within 10 percent tolerance, a goal which was really never met even when 
the test frequency was lowered from 15 to $5 \mathrm{MHz}$. Although a spread of 2 $\mathrm{db}$ for amplitude blocks is unacceptable, $2 \mathrm{db}$ tolerance at $5 \mathrm{MHz}$ is presently written in this standard.

Many people have felt that standardization of the ultrasonic system using test blocks and ball targets is not enough. It is necessary to be assured that acceptable techniques for separately measuring transducers and the electronic parameters of the instrument are available. For this purpose, ASTM Section E07.06.09 was formed. Group A establishes and writes procedures or recommended practices for measuring the various transducer parameters. Group B establishes procedures for measuring the electronic characteristics of the various modules of the ultrasonic instrument: the pulser, receiver, video section and alarm circuits. Group C develops the characteristics of instruments for use in hostile environments. Group D reviews various international documents on standardization for input to the ISO TC 135 Group, which reports to ANSI through ASTM. Group G is dealing with the identification of vertical linearity of the instrument. The present practice is covered by ASTM E-317. Group $E$ is preparing an improved document that can be used for looking at a total system in the field. The document provides a relatively quick check for the average technician or engineering aid to ascertain whether the system is functioning properly.

The impact of the ASTM output will be that, for the first time, the engineer and instrument designer will have a set of specifications to guide instrument design. He will have measurement methods so that he can specify values for such parameters as resolution, sensitivity, signal-to-noise; vertical and horizontal linearity, etc. The intent of the ASTM Group will be not only to provide a recommended practice useful to the instrument manufacturers, but also to the customer of the instrument. As part of the program, the procedures for testing the various components will be outlined in such a way that any well-equipped electronics laboratory can make its own measurements. There again, we feel that this will be the first time that there will be agreement on test procedures and the evaluation of the various parameters.

When the above is accomplished there should be no excuse for the instrument being an unknown quantity, which has been nentioned a number of times at this workshop. This program will impact not only on the reliability of a particular product but also on the liability that so many companies are worried about. Consequently, the implication of this standardization program to industry as a whole will mean safer and more reliable products.

It was noted that the pattern followed in this workshop very closely resembled the pattern of discussion in ASTM Subcommittee E7.06. However, this should not be surprising since these are the same problems that experts have been thinking about for a number of years. 
There still are, of course, some problems with some ASTM specifications. Data indicates changing search units can introduce a vartability of more than 25 percent in tests with blocks, yet all of the six search units involved in a test at NBS were acceptable according to current ASTM specification E127-75. Obviously, improvements in this specification are needed to meet the ASTM goals. Blocks shorter than $1 / 2$ Inch metal distance cannot be checked using ASTM E127 specification because of near surface resolution. Yet ASTM E317 recommends the use of a $1 / 8$ inch metal travel block for checking resolution.

Section E7.06.10 is addressing the problem of steel reference blocks and applying correction factors to ultrasonic examination of steel with cylindrically curved surfaces.

\section{The Role of NBS}

Many statements, suggestions, needs, etc. were ralsed regarding the role of NBS in ultrasonic NDE standards.

1. The suggestion was raised that perhaps NBS should act as a clearinghouse for developments in NDE and medical diagnosis to provide a cross path for 1deas in one area to get to the other.

2. The complaint was raised several times that standards in general are not traceable to NBS.

3. NBS does very little in the way of standards setting, although it does work very closely with the standards organizations in helping them introduce standards which industry recognizes and uses. One of the basic functions of NBS is to service measurement systems, which distinguishes it from a regulatory role. NBS defines proper measurements and provides the means for making such measurements. It is necessary to define an acceptable uncertainty in the measurements with the same material and equipment and with different pieces of equipment at various locations.

4. There is a hierarchy of calibrations, some which NBS alone might use, and others that might be used in fleld laboratories.

5. In a proper measurement system it is helpful to deal with obstacles that are theoretically characterized; this provides an understanding of the standards and calibration procedures at a basic level. However, the proper role of theory in ultrasonic NDE standards has not been clarifled. For example, is 1 t more useful to know the absolute scattering or rather to use theory as a means of transferring a calibration or standard from one situation to another?

6. There is an important question regarding the conditions under which components should be evaluated in order to make the results meaningful. Thiş question arises, in particular, in assessing how 
components interact with one another and how different transducers affect the pulser. This was suggested as an area for NBS involvement.

7. NBS should provide industry with a recommended practice for field measurement of the electronic instrumentation and transducer characteristics, a difficult problem. The NBS approach at present, however, is to offer a transducer calibration service. This calibrated transducer can be compared against others and determine, for example, what properties one wants from that transducer. It was emphasized again that NBS is not a regulatory agency.

8. NBS should develop a standard for imaging which would serve as an all-purpose one and have the following properties. (a) It is based on a theoretical model so that one can understand what is happening. (b) It would simultaneously check the lateral, transverse and depth resolution of a system. (c) It would have a range of structure inside of it so that you could get an acoustic impedance ratio to check on the contrast. It might be possible for one block to be useful in the range from 1 to $25 \mathrm{MHz}$. It would be necessary to work out the ranges on impedance ratios to span a range of contrasts. It might be necessary to have one block for each impedance ratio. (d) The program should treat the three-dimensional problem.

In the short term, the problem is simply to get meaningful standards. For example, the electronic problem can probably be handled today, and its solution could go a long way to satisfying some of the current needs. In the 5 to 10 year period, however, near and far term solutions would provide the capability for a quantitative system which, moreover, would serve as a standard for people with simpler problems.

9. If quantitative NDE capability is going to have a major impact in the whole role of $\mathrm{NDE}$, what is the role of standards? This is a question that the NBS/ARPA program will address. Do we even need standards if with imaging systems we can really measure the size, shape, and orientation of defects?

10. Another area which would fit the NBS charter well and be meaningful to everybody is to establish a program to make quantitative measurements on the acoustic properties of materials, particularly on attenuation and ultrassnic scattering. Very little technology has been developed to make such quantitative measurements in the frequency domain of ultrasonic NDE. One cannot go to a handbook and obtain acoustic attenuation and scattering values to determine, for example, that a number one hole in 304 stainless steel could be used to provide a specified reflection. Such measurements cannot be made with ordinary flaw detection equipment. The attenuation should be measured as a function of frequency and also orientation because anisotropy should be considered. Such a compilation would be rather complicated but useful. The ultimate object may be to establish a signal-to-noise ratio 
for materials, 1.e., a detectability number related to a disc or spherical scatterer or whatever as a function of frequency and distance.

11. NBS plans to address forward-looking problems. Nevertheless, it would be a mistake to totally address problems that might need to be solved in the future and ignore near-term problems that will impact conventional systems (and future systems) destined to be used for many years.

12. An overlap in the deliberations of this workshop and ASTM Subcomittee E-7.06 was noted but not found to be surprising that a group of experts should consider similar directions. Regarding this overlap in ASTM and NBS, close cooperation is needed to avoid duplicating efforts on the one hand and to make more rapid progress in these complex areas than would otherwise be possible on the other hand. stated:

The following near term goals of the NBS ultrasonic program were

- Work will continue to provide calibrations for flat bottom hole reference blocks in aluminum and pursue the development of suitable blocks for steel and titanium.

- Develop fatigue cracks that are well characterized with regard to ultrasonic response.

- Pursue field point characterization of pulsed transducers.

- Provide a theoretical model of the transducer. The model of the infinite baffle piston transducer is not accurate enough. If for CW excitation, we suppose zero velocity at the edge, the results of the axial profile are much different than for uniform velocity.

- There is a definite need for the evaluation of transducers when loaded, if not by the material actually inspected, at least by something with a reasonably similar impedance.

- At present, there is no agreement on what variables should be measured in an instrument or how to measure those variables. The NBS role will not be to specify instrument accuracy, it will be to determine what kind of measurements are appropriate.

Some future directions were suggested:

- Preparation of samples to make rellable measurements of residual stress.

- Develop clear analytical procedures that could be used in the design of transducer and possibly improve their performance and rellability.

- Develop product standards by developing a procedure for producing cracks by applying a given stress function for a given loading program to produce a reasonably uniform fatigue crack.

- Make attenuation measurements. 
- The NBS role in the imaging area is not at present clear. However, there is the possiblity of reference images such as used in radiography, for example.

\section{Summary of the Workshop 11}

1. It is necessary to clarify the distinction between calibration, reference and set-up standards, and develop a common usage.

2. It seems that one type of block, electronic standard or one type of instrument in NDE, or for that matter in any field, cannot be expected to do all.things for all people. Since a variety of types has to be avallable, the question then is how many different varieties.

3. Regarding European versus U.S. Standards, perhaps we should examine our system especially with regard to the use of minimal requirements.

4. There was a great deal of discussion on transducers as the most critical, non-reproducible component, although more comment was made regarding the need to standardize the operator.

5. If one has a thorough understanding of the theoretical concepts involved in any process, that is certainly an assistance in making the measurements. Conversely, since the measurements are required to substantiate the theory, there is a great deal of interplay.

6. For most commercially available transducers that are conventionally used, the plane wave approximation works. The vibrating piston type of theoretical treatment seems to give a falrly good representation of measurements in a number of cases. However, examination of the vibration of a plezoelectric element shows that it acts quite unlike a vibrating piston. On a time average the piston idea may work fairly we11, although it does not really vibrate as a piston. The piston approach was said not to be correct for the receiver mode.

7. Regarding beam profiles, the technique using a microprobe is superior to that using the sphere in water. In elther case, it should be emphasized that the wave fields in solids are quite different from those in water.

8. As a result of work at NBS, it was found that metallurgical variations were responsible for most of the variability of results in blocks tested in a round robin survey. With metals, one has to be concerned about composition, homogenelty, texture and surface conditions. Although making uniform, homogeneous metal in quantity is very difficult, it might be possible to reach such a goal by suitable process control.

TIPresented at the workshop by Prof. R. Green. 
9. The wide variety of blocks which have been used or proposed were discussed. These include: flat bottom hole, an angle flat bottom hole, side drilled hole, diffusion bonded sphere, steel ball in luctte, steel ball in water and triangular slot. In the opinion of this reviewer, a specific defect standard, although very difficult to fabricate in general, would be the best of all.

10. The great variability in the performance of instruments, even the same type of instrument by the same manufacturer, was the subject of much discussion.

11. One will need a set of reference images for ultrasonic imaging systems similar to those currently used in radiography.

12. The point "garbage in equals garbage out" scored. The computer cannot possibly help this situation but only make it worse.

13. The operator competence and reliability problem looms as a very large one.

14. We should pay attention to the list of criteria being developed to assess the wide variety of blocks that are being used or will be proposed. 
Mr. Harold Berger

National Bureau of Standards

Washington, DC 20234

Dr. George B1rnbaum

National Bureau of Standards

Washington, DC 20234

Mr. J. E Bobbin

Rrautkramer Branson Inc.

250 Long Beach Blvd.

Box 408

Stratford, CT 06497

Dr. M. Buckley

ARPA

1400 Wilson Blvd.

Arlington, VA 22209

Mr. R. I. Buckley

Texas Instruments Inc.

P. O. Box 941

Attleboro, MA 02703

Mr. C. E. Burley

Reynolds Metals Company

4th \& Canal Streets

Richmond, VA 23261

Mr. H. H. Chaskells

Naval Research Laboratory

Code 8435

Washington, DC 20375

Mr. Dantel J. Chwirut

National Bureau of Standards

Washington, DC 20234

Dr. Roger B. Clough

National Bureau of Standards

Washington, DC 20234

Mr. D. L. Conn

Research Center

Armco Steel Corp.

Middletown, OH 45042

Mr. John Cope

Newport News Sh1pbullding \& Drydock

Department $\mathrm{X03}$

Newport News, VA 23607

Dr. James Couchman

General Dynamics Corp.

Applied Research

P. 0. Box 7258

Fort Worth, TX 76101
Mr. Ben Cross

Rockwel1 International

Rocky Flats Division

P. 0. Box 888

Golden, CO 80401

Mr. George A. Darcy

Industrial Applications Branch

Army Materials and Mechanics

Research Center

Watertown, MA 02172

Dr. Donald G. E1tzen

National Bureau of Standards

Washington, DC 20234

Prof. J. R. Frederick

2046 E. Englneer1ng B1dg.

Dept. of Mechanical Englneering

Untversity of Michigan

Ann Arbor, MI 48103

Dr. Harold Frost

Applied Research Laboratories

The Pennsylvania State Univ.

P. 0. Box 30

State College, PA 16801

Dr. V. S. Goel

USG Nuclear Regulatory Comm.

Washington, DC 20555

Mr. Sam Golan

National Bureau of Standards

Washington, DC 20234

Dr. Robert Green

Johns Hopkins University

Mech. \& Mat1s. Sclence Dept.

Baltimore, MD 20218

Dr. Logan E. Hargrove

Office of Naval Research

Code 421

800 N. Quincy Street

Arlington, VA 22217

Mr. S. D. Hart

Naval Research Laboratory

Code 8435

Washington, DC 20375

Dr. Nelson Hsu

National Bureau of Standards

Wash1ngton, DC 20234 
Dr. L. C. Iannie110

Chlef, Mtlurgy \& Cer. Bra. Materials Sclence office Division of Physical Research U.S. Energy Res. \& Dev. Admin. Washington, DC 20545

Mr. Stanley Rl1ma

NASA Lew1s Research Center 21000 Brook Park Road Cleveland, OH 44135

Mr. W. E. Lawrie

Babcock \& W1lcox

P. 0. Box 1260

Lynchburg, VA 23305

Dr. Hasse11 M. Ledbetter National Bureau of Standards Boulder, CO 80302

Dr. Melvin Linzer

National Bureau of Standards

Washington, DC 20234

Mr. Robert W. McClung

Oak RIdge National Laboratory

P. 0. Box X

Oak RIdge, TN 37830

Mr. P. C. McEleney

U. S. Army Materials \& Mechanics

Research Center

Arsenal Street

Watertown, MA 02172

Dr. Bric Miller

National Bureau of Standards

Washington, DC 20234

Dr. Leonard Mordfin

National Bureau of Standards

Washington, DC 20234

Mr. G. J. Posakony

Battelle Northwest

Box 999

Rlchland, WA 99352

Mr. Charles F. Raatz

Specialist Engineer

Boelng Commerical Alrplane Co.

Seattle, WA 98109

Mr. Rlchard Rowand

Technical Manager for NDT

Alr Force Materlals Laboratory

Wright-Patterson AFB, OH 45433
Dr. Wolfgang Sachse

National Bureau of Standards

Wash1ngton, DC 20234

Mr. Roneld Selner

Unfversal Technology Corp.

1656 Mardon Drive

Dayton, OH 45432

Prof. Steven Serablan

Mechanical Englneering Dept.

Lowell Technological Institute

Lowe11, MA 01854

Mr. S. I. Shelton

Lead Englneer - NDT

Vought Corporation

P. 0. Box 5907

Dallas, TX 75222

Dr. John S1mons

National Bureau of Standards

Washington, DC 20234

Mr. W11lam H. Sproat

Materlals Development Laboratory

Lockheed - Georgla Co.

Marletta, GA 30063

Dr. Donald Thompson

Director, Structural Materials

Center for Advanced NDE

Rockwell International ScIence

Center

1049 Camino Dos Rtos

Thousand Oaks, CA 91360

Dr. R. Bruce Thompson

Rockwell International Sclence

Center

1049 Camino Dos R1os

Thousand Oaks, CA 91360

Dr.H. H. Vanderveldt

Naval Sea Systems Command

Code 03522

Department of the Navy

Washington, DC 20362

Dr. E. C. van Reuth

Assistant to Director,

Materlals Research

Defense Advanced Research Projects

Agency

1400 W11son Blvd.

Arlington, VA 22209

Mr. H. E. Van Valkenberg

Automation Industries Inc.

P. 0. Box 3500

Danbury, CT 06810 
Welcome and Introduction - H. Berger, National Bureau of Standards

1. View of Current Ultrasonic NDE Standards -- Moderator: D. G. Eitzen, National Bureau of Standards

a. Rationale for Existing ASTM Standards -- H. E. Van Valkenberg, Automation Industries, Inc.

b. Current NBS Program -- D. J. Chwirut, National Bureau of Standards

c. Problems in Ultrasonic Testing and Standards -- G. J. Posakony, Battelle Northwest Laboratory

d. Some Criteria for a System of Ultrasonic NDE Calibrations and Standards -N. Hsu, National Bureau of Standards

e. European Philosophy, Practices and Standards -- W. E. Lawrie, Babcock and Wilcox

2. Recent Developments in Ultrasonic NDE: Implications for Standards -- Moderator: D. 0. Thompson, Rockwell International Corp.

a. Scattering Methods - R. B. Thompson, Rockwell International Corp.

b. Transducers and Arrays -- W. H. Sachse, Cornell UnIversity and Natlonal Bureau of Standards

c. Imaging Systems -- S. Hart, Naval Research Laboraţory

d. Signal Processing -- M. Linzer, National Bureau of Standards

e. Automation -- J. C. Couchman, General Dynamics Corporation

3. Ultrasonic NDE Needs in Industry: Implications for Standards -- Moderator: R. H. Selner, Universal Technology Corporation

a. Aerospace -- W. H. Sproat, Lockheed-Georgia Corporation

b. Nuclear -- R. W. McClung, Oak Ridge National Laboratory

c. Raw Materlals -- S. I. Shelton, Vought Corporation

d. NDE Equipment - R. I. Buckley, Texas Instruments

4. Ultrasonic NDE in Government: Current Problems, Future Needs and Implications for Standards -- Moderator: E. Van Reuth, ARPA.

a. Alr Force -- R. Rowand, Alr Force Materials Laboratory

b. Navy -- H. H. Vanderveldt, Naval Sea Systems Command

c. Army -- G. Darcy, Army Materials and Mechanics Research Center

d. Advanced Research Projects Agency -- M. Buckley, ARPA

- e. Nuclear Regulatory Commission -- V. S. Goel, NRC

f. Energy Research and Development Administration -- L. C. Ianniello, ERDA

8. National Aeronautics and Space Administration -- S. Klima, NASA Lewis Space Flight Center

5. Summary, Comments and Critique -- Moderator: G. Birnbaum, National Bureau of Standards

a. Problems and Needs for Standards -- R. E. Green, Johns Hopkins University

b. Future Directions -- D. G. Eitzen, Natlonal Bureau of Standards 


\section{APPENDIX B \\ Qualitative Examination of Some Novel Blocks}

At the outset of this study it was thought worthwhile to initiate some very limited laboratory effort related to alternative ultrasonic standards. It was decided that hands-on experience with several novel blocks which could be easily obtained would be useful. Three types of blocks were chosen for qualitative examination.

A. Spherical Reflectors - There has been continuing interest in incorporating spherical reflectors in reference blocks. The interest in spheres is not particularly new since in fact the primary reference for the ASTM aluminum reference block system as pubiished by ASTM in 1958 is a sphere in water. Tests for ultrasonic equipment for medical applications also make use of a sphere. The key advantages that ASTM recognized in the sphere were the clean theoretical description available (a linear relationship between amplitude and ball diameter) and the reproducibility and availability of the ball bearings used as reflectors in water. However, for a field standard it is convenient to have the sphere embodied in some material with a definite geometry. We consider here in a cursory way three embodiments of this geometry:

1. a spherical vold in a titanium cylinder fabricated by diffusion bonding,

2. a spherical void in glass,

3. a steel ball bearing in an acrylic cylinder.

Note that two of these are in transparent material with a view toward the design of material-independent blocks.

B. Side Drilled Hole - A side-drilled hole in a polygonal glass plate was fabricated. The interest here was in another embodiment of a theoretica? describable reflector in a transparent material. The side-drilled hole is favored by some workers since it easily serves for both longitudinal and angle beam testing.

C. Conical Block - Blocks of aluminum with truncated conical ends were fabricated. This geometry preserves the advantages of (primarily) a disc reflector in a block which is easier to machine and dimensionally to verify than a flat-bottomed-hole.

\section{Experimental results}

Essentially qualitative tests were conducted using a wide band laboratory type pulser-receiver and a wide band $10-\mathrm{MHz}$ transducer. 
1. Titanium diffusion-bonded block with a spherical void ${ }^{2}$. Since the spherical void was located midway along the cylindrical axis, the reproducibility of the return from two faces could be determined. It was necessary to gate close to the back scattered waveform from the sphere because of nonreproducible, nonidentifiable signals, probably due to grain boundary scattering. It was noted that the apparent attenuation was quite high. The amplitude of the back scattered signal of the sphere obtained from the two faces did not agree very well. However, the integral of the power spectrum obtained by a fast Fourier transform of the gated reflections from the sphere gave agreement between the signals from the two ends within about $3 \mathrm{~dB}$.

The results from this particular specimen were disappointing since even the agreement of the integrated power spectrum was unsatisfactory. Nonetheless, better results could likely be obtained with additional fabrication or material controls.

2. Spherical void in glass

An Orrefors paperweight (designed by 0lle Alberius) contains a spherical void in glass. The diameter of the sphere is estimated to be about $7 / 16$ in and consequently much larger than the wavelength at $10 \mathrm{MHz}$. The upper part of the "block" containing the void is a pentagonal pyramid. It was found that the reflections obtained from each of the sides of the pyramid agreed extremely well. Moreover, the reflected waveform was in close agreement with theoretical predictions [42]. It was easy to visualize the sound field due to an ultrasonic pulse reflecting fron the hole in glass using photoelastic methods [17]. On the basis of these results and in light of the low cost, it appears that such a glass block could be considered for possible development. However, reproducibility of sphere size, for example, was not determined since only one specimen was investigated.

3. Ball bearing in acrylic

An easily formed specimen makes use of a ball bearing in a polyresin cylinder. The sphere is cast in the resin. Of course other outer geometries are easily obtained. Fabrication is extremely simple with the reflector geometry being very reproducible. However, there are questions of resin variation, moisture control and long term stability. Also, the resin is

12 obtained by W. Sachse from B. Tittman. 
rather lossy. A controlled fabrication process may improve the reproducibility. Despite the disadvantage of high attenuation, its transparency, ease of fabrication and low cost make a case for further consideration of such a specimen, possibly with a lower attenuation resin.

B. Side-drilled hole in a glass plate

Another manifestation of a transparent block easily fabricated is a hole drilled through a plate with polygonal sides. The specimen used had nine sides which were equidistant from the side-drilledhole. One would expect very good agreement among the reflections from the various sides. Agreement only within about $1 \mathrm{~dB}$ in the amplitude of the reflected signal was obtained. The side-drilledhole was observed to be less than perfect and could account for some of the variations. On the basis of these very preliminary measurements, this geometry could also merit further study.

\section{Truncated cone}

Several specimens were prepared from aluminum in the geometry of a block with a conical truncated end. This provides a disc reflector for waves which go through the block and reflect from the truncated surface. The metal travel distance and disc size were fabricated to correspond to a few of the blocks in the ASTM-type FBH block series. The return signal from the disc appeared to be somewhat distorted by reflections and interference from the adjoining conical surface. In addition, this effect might also lead to a relationship between disc area and reflection amplitude which is not nearly as nice as the very linear one associated with FBH blocks. It was noted that the amplitude of the reflection was significantly different from that of an FBH block with the same size disc reflector and metal travel distance. The economies of fabrication and dimensional checks are apparent. While this geometry is interesting, additional work would certainly be necessary before this block could be given serious consideration for use in NDE measurements.

Conclusions.

This laboratory effort was of such limited scope that no conclusions based on data can be drawn on the relative merits of the different block concepts. No statistical information was developed since only one specimen of each type was examined. Where possible, however, multiple paths were examined and in one case these showed rather large differences. The one conclusion that can be drawn is that even in the case of very simple geometries considerable care and effort are required to obtain reproducible results. 

NBS-114A (REV. 9-76)

\begin{tabular}{|c|c|}
\hline $\begin{array}{c}\text { U.S. DEPT. OF COMM. } \\
\text { BIBLIOGRAPHIC DATA } \\
\text { SHEET }\end{array}$ & 1. PUBLICATION OR REPORT NO. \\
\hline
\end{tabular}

\section{TITLE AND SUBTITLE}

An Appraisal of Current And Future Needs In U1trasonic NDE Standards

\section{AUTHOR(S)}

George Birnbaum and Dona1d G. Eltzen

\section{PERFORMING ORGANIZATION NAME AND ADDRESS}

NATIONAL BUREAU OF STANDARDS

DEPARTMENT OF COMMERCE

WASHINGTON, DC 20234

12. SPONSORING ORGANIZATION NAME AND COMPLETE ADORESS (Stroot, City, stalo, zIP)

\section{SUPPLEMENTARY NOTES}

Document describes a computer program; SF-185, FIPS Software Summary, is attached.

16. ABSTRACT (A 200-word or loss factual summary of most oigrificant information. If document includes a oignificant bibitography or ilterature survey, mention it here.)

The purpose of this study, supported in part by DARPA, is to assess the current status of NDE ultrasonic standards and calibrations and to determine current and future needs in this area. The source material includes surveys of the literature and patents, a study of foreign practice, surveys of NBS and consensus standards (e.g. ASTM) programs, discussions, visits and letters, and a Workshop on U1trasonic NDE Standards: "Current Needs and Future Directions", held October 17-18, 1977 for the purpose of implementing the objectives of this study. Recommendations for improvement in existing standards will. impact primarily on conventional pulse echo systems and include work on transducers, the electronic system and reference blocks.

17. KEY WORDS (oix to twoive onteloo; alphabeticai order; capitatise only the firat ietter of the firat key word unieas a proper neme; soparatod by somicoions)

Calibrations; flaw geometry; future needs; orlentation; pulse echo systems; quantitative measurements; reference blocks; ultrasonic NDE standards; and ultrasonic transducers.

$\square$ Unlimited

For Official Distribution. Do Hot Release to NTIS

Order From Sup. of Doc., U.S. Government Printing Office, Washington, DC 20402, SD Stock No. SNÖ03-003-

$\square$ Order From National Technical Information Service (NTIS), Springfield, VA. 22161

\begin{tabular}{|l|l|}
\hline $\begin{array}{l}\text { 19. SECURITY CLASS } \\
\text { (THIS REPORT) }\end{array}$ & $\begin{array}{l}\text { 21. NO. OF } \\
\text { PRINTED PAGES } \\
\text { UNCLASSIFIED }\end{array}$ \\
\hline $\begin{array}{l}\text { 20. SECURITY CLASS } \\
\text { (THIS PAGE) } \\
\text { UNCLASSIFIED }\end{array}$ & 22. Price \\
\hline
\end{tabular}



